\title{
Air-sea fluxes of oxygenated volatile organic compounds across the Atlantic Ocean
}

\author{
M. Yang ${ }^{1}$, R. Beale ${ }^{1}$, P. Liss ${ }^{2,3}$, M. Johnson ${ }^{2,4}$, B. Blomquist ${ }^{5}$, and P. Nightingale $^{1}$ \\ ${ }^{1}$ Plymouth Marine Laboratory, Prospect Place, Plymouth, UK \\ ${ }^{2}$ School of Environmental Sciences, University of East Anglia, Norwich, UK \\ ${ }^{3}$ Department of Oceanography, Texas A \& M University, College Station, TX, USA \\ ${ }^{4}$ Centre for Environment, Fisheries and Aquaculture Science, Lowestoft, UK \\ ${ }^{5}$ Department of Oceanography, University of Hawaii, Honolulu, HI, USA
}

Correspondence to: M. Yang (reelguy@gmail.com)

Received: 4 March 2014 - Published in Atmos. Chem. Phys. Discuss.: 24 March 2014

Revised: 30 May 2014 - Accepted: 18 June 2014 - Published: 24 July 2014

\begin{abstract}
We present air-sea fluxes of oxygenated volatile organics compounds (OVOCs) quantified by eddy covariance (EC) during the Atlantic Meridional Transect cruise in 2012. Measurements of acetone, acetaldehyde, and methanol in air as well as in water were made in several different oceanic provinces and over a wide range of wind speeds (1$18 \mathrm{~m} \mathrm{~s}^{-1}$ ). The ocean appears to be a net sink for acetone in the higher latitudes of the North Atlantic but a source in the subtropics. In the South Atlantic, seawater acetone was near saturation relative to the atmosphere, resulting in essentially zero net flux. For acetaldehyde, the two-layer model predicts a small oceanic emission, which was not well resolved by the EC method. Chemical enhancement of air-sea acetaldehyde exchange due to aqueous hydration appears to be minor. The deposition velocity of methanol correlates linearly with the transfer velocity of sensible heat, confirming predominant airside control. We examine the relationships between the OVOC concentrations in air as well as in water, and quantify the gross emission and deposition fluxes of these gases.
\end{abstract}

\section{Introduction}

Oxygenated Volatile Organic Compounds (OVOCs) including acetone, acetaldehyde, and methanol are present ubiquitously in the lower atmosphere. The sum of these three gases accounted for $37-63 \%$ of the total (non-methane) observed organic carbon (gaseous and particulate) in remote marine air (Heald et al., 2008). OVOCs influence the tropospheric oxidative capacity and air quality by influencing the cycling of ozone and the hydroxyl radical (Carpenter et al., 2012). In the surface ocean, dissolved OVOCs represents a source of energy and carbon for microbes (Dixon et al., 2013). Dachs et al. (2005) estimated a large net air-to-sea flux of gaseous total organic carbon (TOC) in the northeast subtropical Atlantic (tens of mmoles $\mathrm{m}^{-2} \mathrm{~d}^{-1}$ ), often similar in magnitude to the $\mathrm{CO}_{2}$ flux. Here we quantify the air-sea fluxes of acetone, acetaldehyde, and methanol. These transport terms are uncertain in not only magnitude, but also in direction due to scarcities of concurrent air/sea concentration as well as direct flux measurements.

Terrestrial plant emissions and atmospheric oxidation of precursors are among the main sources of atmospheric acetone in global models (e.g. Jacob et al., 2002; Fischer et al., 2012). The role of the ocean towards the acetone budget is less clear. Earlier estimates of the net air-sea acetone flux range between $-14 \mathrm{Tg} \mathrm{yr}^{-1}$ (Singh et al., 2003) and $13 \mathrm{Tg} \mathrm{yr}^{-1}$ (Jacob et al., 2002) globally, with the positive/negative sign indicating emission/deposition. Based on eddy covariance (EC) measurements (with atmospheric pressure ionization mass spectrometry) over the Pacific, Marandino et al. (2005) estimated a much greater net deposition of $-48 \mathrm{Tg} \mathrm{yr}^{-1}$ globally. Other observations at sea (Taddei et al., 2009; Beale et al., 2013; Tanimoto et al., 2014) indicate the air-sea flux of acetone to be small and variable in sign temporally as well as spatially, similar to recent model estimates from Fischer et al. (2012). 
Terrestrial plants and atmospheric oxidation of precursors are the main sources of atmospheric acetaldehyde (Guenther et al., 2000; Jardine et al., 2008; Millet et al., 2010). Large oceanic emission of acetaldehyde has been estimated in global models, spanning from $57 \mathrm{Tg} \mathrm{yr}^{-1}$ (Millet et al., 2010) to $125 \mathrm{Tg} \mathrm{yr}^{-1}$ (Singh et al., 2003). From in situ seawater concentrations in the Atlantic, Beale et al. (2013) calculated a much lower oceanic emission (mean of $17 \mathrm{Tg} \mathrm{yr}^{-1}$ ) than those earlier estimates. These discrepancies are partly due to different treatments of chemical enhancement in the computation of air-sea acetaldehyde exchange (see Sect. 4.2). To our knowledge, the air-sea flux of acetaldehyde has never been directly measured over the open ocean.

Atmospheric methanol mainly originates from terrestrial plants, with additional sources from biomass and biofuel burning, industrial emissions, and atmospheric oxidation of precursors (Guenther et al., 2000; Singh et al., 2000; Heikes et al., 2002; Jacob et al., 2005; Millet et al., 2008). Photochemical destruction, deposition to land (Karl et al., 2004), and to the ocean surface (Heikes et al., 2002; Williams et al., 2004; Carpenter et al., 2004) remove atmospheric methanol. Based on in situ seawater concentrations, Beale et al. (2013) estimated both positive and negative methanol fluxes, with a mean net oceanic emission of $12 \mathrm{Tg} \mathrm{yr}^{-1}$. From the cruise detailed in this paper, Yang et al. (2013b) measured a consistent deposition of methanol into the ocean by EC that extrapolates to $-42 \mathrm{Tg} \mathrm{yr}^{-1}$ globally. The discrepancy in these estimates illustrates the large uncertainties remaining in our understanding of methanol cycling.

On the 22nd Atlantic Meridional Transect (AMT-22) cruise, we directly measured the air-sea fluxes of acetone, acetaldehyde, and methanol by EC with a high sensitivity proton-transfer-reaction mass spectrometer (PTR-MS, Ionicon Analytik, Austria, first described by Lindinger et al., 1998). The results for methanol have been published previously (Yang et al., 2013b); we include them here for completeness of the data set, as well as to explain the methodology in detail and compare the relationships between the three gases. In recent years the PTR-MS has been used with the EC method to measure the vertical fluxes of OVOCs at terrestrial sites (e.g. Karl et al., 2001; Yang et al., 2013a). In comparison, the application of EC on a ship is challenged by motion-induced artifacts as well as generally lower fluxes. Our effort here, to the best of our knowledge, represents the first utilization of the PTR-MS for EC flux measurements at sea. We also measured the concentrations of these compounds in seawater with the same PTR-MS as used for the atmospheric measurements coupled to a membrane inlet (described by Beale et al., 2011). This allows us to compare EC fluxes with predicted net fluxes based on the two-layer model (Appendix A).

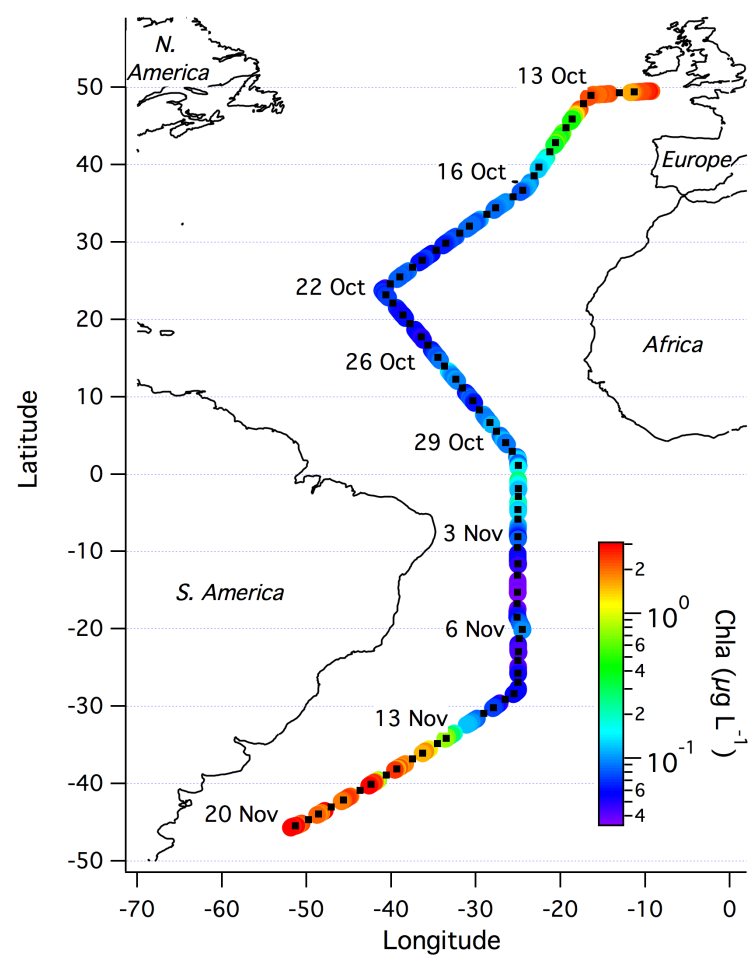

Figure 1. Cruise track of AMT-22 (2012) color-coded by chlorophyll a concentration and marked on selected dates. The black squares indicate the locations of CTD casts.

\section{Experimental}

The sampling track of AMT-22 cruise from Southampton, UK to Punta Arenas, Chile in 2012 on the Royal Research Ship James Cook is shown in Fig. 1, color-coded by chlorophyll $a$ concentration (measured by fluorescence and verified by absorption) and marked on selected dates. Aside from stopping twice a day for Conductivity Temperature Depth (CTD) casts, the ship steamed steadily at a regular speed and heading. The annual voyage (www.amt-uk.org) contributes to a long-term time series of biological, chemical, and physical oceanographic parameters across the Atlantic and allows us to examine the magnitude and variability of air-sea OVOC exchange across different regions.

\subsection{Atmospheric OVOC concentrations $\left(C_{\mathrm{a}}\right)$}

The PTR-MS was located in the meteorological laboratory near the foredeck of the ship. All data (concentration, wind, motion, flow) were logged on the same computer, which was synchronized to the GPS clock daily. For $\sim 19 \mathrm{~h}$ of a day, the PTR-MS sampled ambient air drawn into the laboratory by a vacuum pump from the meteorological platform above ship's bow $(z=18 \mathrm{~m}$ a.m.s.l.) via $\sim 25 \mathrm{~m}$ of $6.4 \mathrm{~mm}$ ID perfluoroalkoxy (Teflon PFA) tubing. The fully turbulent manifold flow $(\sim 23$ standard liters per minute, Reynolds number of $\sim 5000$ ) was recorded by a digital thermal mass flow 
meter (Bronkhorst EL-FLOW series). Nominal settings of the PTR-MS were as follows: drift chamber temperature of $80^{\circ} \mathrm{C}$, voltage of $700 \mathrm{~V}$, and source water vapor flow of 9 standard cubic centimeter per minute ( $\mathrm{sccm})$. Instrument sensitivity typically increased with the chamber pressure, which was regulated such that the $m / z 37$ signal $\left(\mathrm{H}_{2} \mathrm{O} \cdot \mathrm{H}_{3} \mathrm{O}^{+}\right)$remained less than $5-6 \%$ of the hydronium source ion $\left(\mathrm{H}_{3} \mathrm{O}^{+}\right)$ signal. This pressure varied from $2.8 \mathrm{mbar}$ in higher latitudes to $2.5 \mathrm{mbar}$ in the tropics due to changes in ambient humidity. The $m / z 32\left(\mathrm{O}_{2}^{+}\right)$signal was $\sim 1 \%$ of $\mathrm{H}_{3} \mathrm{O}^{+}$, which averaged $\sim 2.5 \times 10^{7}$ counts per second (cps) during the cruise.

Continuous internal isotopic standards were used to account for drifts in reaction rates and transmission efficiencies in the PTR-MS. Deuterated methanol (d3-methanol, with protonated mass to charge ratio $\mathrm{m} / \mathrm{z}$ of 36) and acetone (d6acetone, $m / z$ of 65$)$ gas standards in nitrogen $(2.0 \pm 0.1 \mathrm{ppm}$, Scientific and Technical Gases Ltd) were injected continuously into the manifold at $\sim 2 \mathrm{~m}$ ahead of the subsampling "tee" for the PTR-MS. The standard flow was regulated by a digital thermal mass flow controller (Bronkhorst EL-FLOW series) at $30( \pm 0.3) \mathrm{sccm}$, resulting in diluted standard concentrations of $\sim 2.6 \mathrm{ppb}$. The main tubing was wrapped with opaque insulating foam to prevent photochemistry and condensation of water in the interior wall.

For most of the cruise, methanol $(\mathrm{m} / \mathrm{z} 33)$, acetaldehyde $(\mathrm{m} / \mathrm{z} 45)$, and acetone $(\mathrm{m} / \mathrm{z} 59)$ were measured under multiple ion detection (MID) mode. The PTR-MS cycled through $m / z 21\left(\mathrm{H}_{3}^{18} \mathrm{O}^{+}\right.$, dwell time of $\left.50 \mathrm{~ms}\right), 33(100 \mathrm{~ms}), 36$ (50 ms), 45 (100 ms), 59 (100 ms), and 65 (50 ms) with total sampling frequency of $\sim 2.1 \mathrm{~Hz}$. Between 3 and 16 November, we chose to measure atmospheric acetaldehyde for only $\sim 2 \mathrm{~h}$ a day (near the times of the CTD casts) because of its low ambient abundance. We also monitored the concentrations of isotopic standards, $\mathrm{H}_{2} \mathrm{O} \cdot \mathrm{H}_{3} \mathrm{O}^{+}$, and $\mathrm{O}_{2}^{+}$from daily scans. The gas standards were stable over the duration of the cruise.

The derivation of atmospheric methanol concentration from isotopic standard addition is detailed by Yang et al. $(2013 \mathrm{a}, \mathrm{b})$. The ambient concentration of atmospheric acetone $\left(C_{\text {acetone }}\right)$ is computed analogously:

$C_{\text {acetone }}=C_{\text {acetone, sd }} \frac{\left(\mathrm{cnts}_{59} / \mathrm{cnts}_{65}\right) A_{65, \mathrm{sd}}-A_{59, \mathrm{sd}}}{A_{59, \mathrm{amb}}}$.

Here $C_{\text {acetonel,sd }}$ is the concentration of $d_{6}$-acetone; cnts 59 and cnts 65 are the signals at $m / z 59$ and 65 after subtracting the backgrounds (see Appendix B for discussion on backgrounds). Mass scans indicates $A_{65, \mathrm{sd}}$, the isotopic ratio of $\mathrm{m} / \mathrm{z} 65$ in the gas standard, to be 0.86 ; we adjust this value to 0.90 to account for the $\sim 4 \%$ higher transmission efficiency expected at $m / z 65$ than at $m / z 59$. The standard gas cylinder contains a small amount of undeuterated acetone, which is represented by $A_{59, \mathrm{sd}}(\sim 0.02$ from mass scans). At 0.96 , $A_{59, \text { amb }}$ is the isotopic ratio of $m / z 59$ in ambient air from natural abundance of elements. The abundance of the deuter- ated isotopomer in ambient air is insignificant and neglected in this analysis.

Because of the unit mass resolution of the PTR-MS, propanal and glyoxal are not distinguished from acetone at $m / z$ 59. Singh et al. (2004) reported $\sim 0.07 \mathrm{ppb}$ of propanal for the lowest $2 \mathrm{~km}$ of the remote tropical Pacific. The low concentration is consistent with its predominant anthropogenic origin and short atmospheric lifetime. From satellite measurements in the UV-visible range, Stavrakou et al. (2009) and Lerot et al. (2010) retrieved a glyoxal column concentration of $1-4 \times 10^{14}$ molecules $\mathrm{cm}^{-2}$ over the Atlantic in the Northern Hemisphere autumn. Even assuming all of the glyoxal is contained within a well-mixed, $1 \mathrm{~km}$ marine atmospheric boundary layer, this corresponds to approximately $0.03-0.12 \mathrm{ppb}$ at ambient temperatures, of the same order as shipboard glyoxal measurements by Sinreich et al. (2010) from the southeast Pacific and a few times lower than typical acetone concentrations. Moreover, glyoxal is probably not ionized efficiently in the PTR-MS due to its low proton affinity (Wróblewski et al., 2007). During AMT22 , predicted fragment ions of propanal and glyoxal were examined with a separate GC-MS system in both air and water of the subtropical North Atlantic but not clearly detected (S. Hackenberg, personal communication, 2012). Nevertheless, measured atmospheric acetone concentrations may be upper limits due to these potential interferences.

The atmospheric acetaldehyde concentration from this cruise is more uncertain due to the lack of a suitable standard, which tends to be unstable in both gas cylinders and permeation devices. We used the low pass filtered source ion count at $m / z 21$, the average kinetic reaction rate presented by Zhao and Zhang (2004), and instrument-specific transmission efficiencies to compute its concentrations. As with Yang et al. (2013a), we further adjust the derived acetaldehyde concentration by the ratio between ambient methanol concentration determined from isotopic dilution and the direct output of the instrument. The noise level $(1 \sigma)$ of the high frequency $(\sim 2.1 \mathrm{~Hz}, 100 \mathrm{~ms}$ dwell time per ion) data were $\sim 0.1,0.1,0.2 \mathrm{ppb}$ for acetone, acetaldehyde, and methanol, respectively. The detection limits $(3 \sigma)$ for mean atmospheric concentrations ( $2 \mathrm{~min}$ average) for these compounds were much lower at $\sim 0.02,0.02$, and $0.05 \mathrm{ppb}$.

A plastic funnel, initially attached to the front of the gas inlet to keep out water droplets, was unexpectedly found to emit compounds at $m / z 45$ and 59. Exposed to sunlight for 6 months continuously prior to this cruise, the funnel appeared to have photochemically degraded over time. Emissions from the funnel were not obvious at the beginning of the cruise under overcast and cool $\left(<15^{\circ} \mathrm{C}\right)$ conditions, but became increasingly pronounced when the ship approached the tropics. Contamination was more severe under direct sunlight and high temperatures than at night, leading to unrealistic diurnal cycles in acetone and acetaldehyde concentrations (Fig. 2). Methanol was not affected. The funnel was removed from the inlet on 29 October $\left(\sim 5^{\circ} \mathrm{N}\right)$ and the 


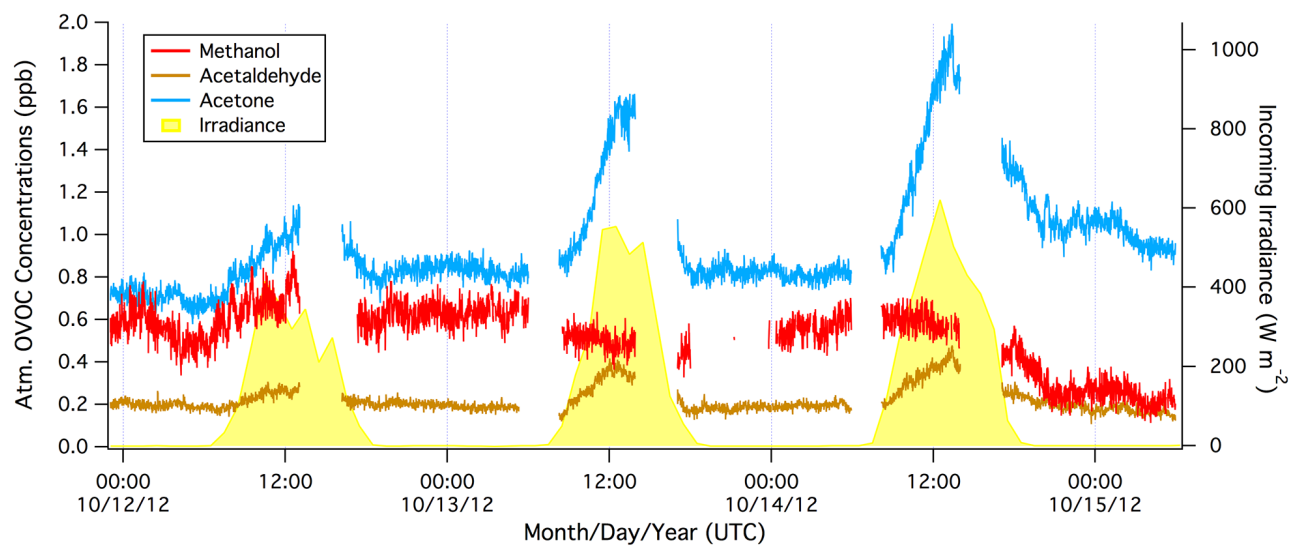

Figure 2. An example of contamination in the acetaldehyde and acetone signals due to outgassing from a plastic funnel at the front of the inlet. The artifact was the most severe under direct sunlight and at high temperatures, leading to unrealistic diurnal cycles. Methanol was not affected. This contamination disappeared immediately after the removal of the plastic funnel on 29 October.

problem disappeared immediately thereafter. However, atmospheric acetone and acetaldehyde data before 29 October were highly uncertain. We discard their daytime data during that period and crudely correct the mean nighttime concentrations for funnel-induced artifacts by detrending with respect to air temperature.

\subsection{Seawater OVOC concentrations $\left(C_{\mathrm{w}}\right)$}

Discrete seawater samples were taken from predawn and noontime CTD casts daily. At each station, triplicate seawater samples were collected from the $5 \mathrm{~m}$ Niskin bottle via a short piece of Tygon ${ }^{\mathrm{TM}}$ tubing into opaque glass bottles to prevent alteration to OVOC concentrations via photochemical reactions. Air contamination was avoided by sampling first from the Niskin, taking care to avoid bubbling, and overfilling the glass bottles for several seconds before capping. To minimize modification of OVOC concentrations by biological activity, water samples were analyzed within $3 \mathrm{~h}$ of collection. OVOCs were extracted from seawater across a semipermeable silicone membrane heated at $50^{\circ} \mathrm{C}$ into a supply of cleaned nitrogen gas flowing directly into the PTR-MS. The first of the triplicates at each station was used to condition the membrane. Reported seawater OVOC concentrations represent the averages of the latter two replicates, which generally agreed within the noise level. Calibration slopes were determined approximately every 2 weeks from equivalent analyses of aqueous standards, which were freshly prepared by serial dilution of reagent-grade OVOCs. The calibration slopes were consistent over the entire cruise, generally varying by less than $10 \%$.

We also took water samples from the deepest Niskin bottle $(\sim 500 \mathrm{~m}$ depth) once a day. The precisions of the seawater measurements were estimated as $3 \sigma$ of eight replicating subsamples from the same bottle of deep seawater $(\sim 8 \mathrm{~L}$ total $)$ taken on 20 November. They were $1.8,0.6$, and $11 \mathrm{nM}$ for acetone, acetaldehyde, and methanol, which represent 13,11 , and $38 \%$ of the respective mean concentrations. In comparison, $3 \sigma$ of the instrument backgrounds of these eight replicates (i.e. signal resulting from the carrier gas alone) were $0.3,0.3$, and $6 \mathrm{nM}$. All OVOC concentrations measured during AMT-22 were above these detection limits.

\subsection{Eddy covariance setup and flux processing}

A 3-D sonic anemometer (WindMaster, Gill) and a 6-channel $(u, v, w$ acceleration and rotation) motion sensor (Motionpak II, Systron Donner) were installed $40 \mathrm{~cm}$ from the air intake. To minimize wind disturbance by the ship's searchlight in the middle, the sensors and inlet were mounted on the starboard side of the meteorological platform and rotated $44^{\circ}$ from the bow. Motion data were measured at $\sim 15 \mathrm{~Hz}$ and later interpolated to match the frequency of winds $(10 \mathrm{~Hz})$. Hourly wind/motion data were processed following Edson et al. (1998) to yield true winds $(u, v, w)$. Further sequential decorrelations of corrected winds with ship velocities and accelerations removed residual motion cross-correlation (Fairall et al., 2000). The resultant motion-corrected wind velocities were used in the hourly EC computations of OVOC fluxes $\left(\overline{w^{\prime} \mathrm{OVOC}}\right)$, sensible heat flux $\left(Q_{\mathrm{H}}=\overline{w^{\prime} T_{\mathrm{a}}^{\prime}}\right)$, and momentum flux $\left(\tau=\rho \overline{w^{\prime} u^{\prime}}\right)$. Here $T_{\mathrm{a}}$ is the sonic temperature corrected for humidity and $\rho$ is air density.

A lag correlation analysis was performed hourly between OVOC and $w$ to determine the delay in atmospheric concentrations relative to wind. The most consistent delay was found in the methanol analysis $(\sim-5.5 \mathrm{~s})$, which is consistent with the expected transit time in the main inlet $(\sim 2 \mathrm{~s})$ and subsampling line followed by reaction chamber $(\sim 3 \mathrm{~s})$. After adjusting for this lag, the OVOC fluxes were computed from the integral of the $C_{\mathrm{a}}$ : $w$ cospectrum from 0.002 to $1 \mathrm{~Hz}$. The uncertainties and detection limits in EC fluxes are discussed in detailed in Appendix C. 


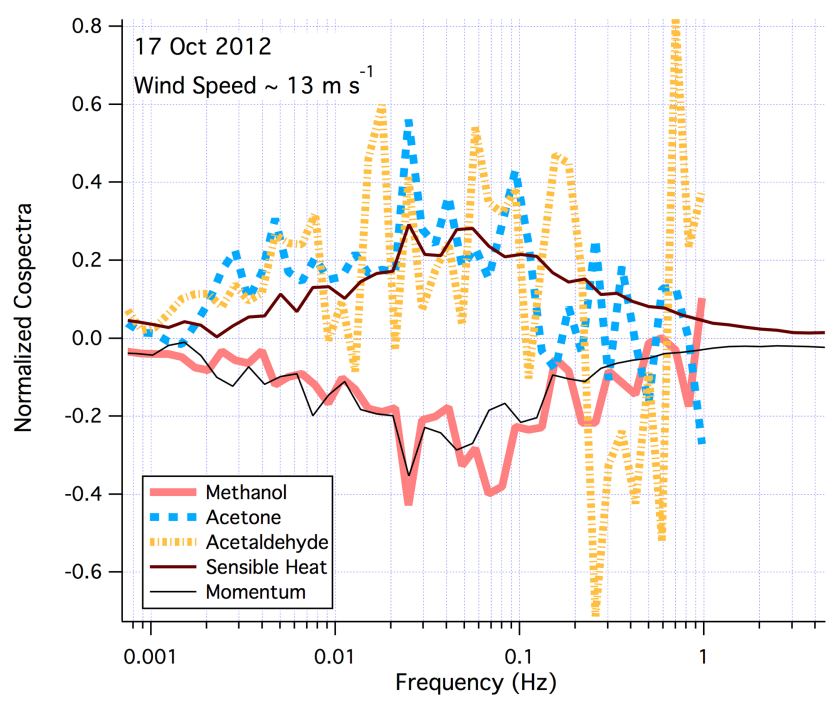

Figure 3. Cospectra of methanol, acetone, acetaldehyde, sensible heat and momentum with the vertical wind velocity on a day of relatively high winds. Each cospectrum is normalized to the respective flux magnitude. Cospectra of heat, momentum, and methanol followed the expected spectral shape, while those of acetone and acetaldehyde were distorted at frequencies above $0.1 \mathrm{~Hz}$, likely due to contamination from the plastic funnel.

To examine the contributions from different frequencies to the turbulent flux, in Fig. 3 we show the cospectra of methanol, acetaldehyde, acetone, sensible heat, and momentum averaged over $10 \mathrm{~h}$ on 16 October $\left(\sim 35^{\circ} \mathrm{N}\right)$, a day of fairly high winds $\left(13 \mathrm{~m} \mathrm{~s}^{-1}\right)$ and moderate swell (vertical platform variance of $\sim 1 \mathrm{~m}^{2} \mathrm{~s}^{-2}$ ). Each spectrum has been normalized by the respective flux magnitude. The heat, momentum, and methanol cospectra all demonstrate the expected spectral shape for atmospheric turbulent transfer (Kaimal et al.1972). In rougher seas, some motion-sensitivity is apparent in the methanol flux, which has been corrected with a decorrelation method (Appendix D). The acetone cospectrum is fairly well defined during this period except for some loss of signal above $\sim 0.1 \mathrm{~Hz}$. The acetaldehyde cospectrum is much noisier and demonstrates large distortions above $\sim 0.2 \mathrm{~Hz}$, likely related to emissions from the plastic funnel (Appendix E); such obviously contaminated data during the daytime are excluded from our analysis below. We also considered the potential contributions to OVOC fluxes due to fluctuations in air density (i.e. Webb et al., 1980), which are insignificant (Appendix F).

With increasing wind speed, the turbulent cospectrum shifts towards higher frequencies, resulting in a greater OVOC flux loss due to the limited sampling rate. Yang et al. (2013a) quantified the high frequency flux attenuation of this system using the Ogive approach (by comparison with the concurrent sensible heat flux, Spirig et al., 2005) and the filter function approach (based on the instrumental response time, Bariteau et al., 2010), which led to similar re- sults. The low signal to noise in both OVOC and sensible heat flux over the ocean limits the usefulness of the Ogive approach. Due to noise in the individual cospectrum, applying the filter function hourly amplifies the scatter in the flux. Instead, we first apply the filter function inversely to theoretical cospectra (Kaimal et al., 1972) calculated at wind speeds of $2-18 \mathrm{~m} \mathrm{~s}^{-1}$. The ratio between the integrals of the Kaimal cospectra and the artificially attenuated cospectra up to the Nyquist frequency yield an effective flux correction factor as a function of wind speed. We further account for the small flux contribution above the Nyquist frequency (usually a few percent) by scaling to the full Kaimal cospectra. The total flux loss ranged from $\sim 10 \%$ to 16 to $21 \%$ at wind speeds of 5,10 , and $15 \mathrm{~m} \mathrm{~s}^{-1}$, respectively.

We limit the relative wind sector to -50 to $110^{\circ}$ and the relative wind speed to $>2 \mathrm{~m} \mathrm{~s}^{-1}$ for flux measurements to avoid airflow distortion from the ship's superstructure and searchlight, as well as contamination in OVOC signals from the ship's exhaust. Hourly constraints for ship maneuvers and the homogeneity/stationarity conditions assumed by EC include $\sigma$ of relative wind direction less than $80^{\circ}, \sigma$ of true wind speed less than $2 \mathrm{~m} \mathrm{~s}^{-1}$, and $\sigma$ of $w$ less than $1 \mathrm{~m} \mathrm{~s}^{-1}$. We compute hourly heat fluxes from the integral of the $T_{\mathrm{a}}: w$ cospectrum over the entire frequency range $(0.00033-5 \mathrm{~Hz})$ as well as over $0.002-5 \mathrm{~Hz}$. Nonstationarity is further identified when $Q_{\mathrm{H}}$ calculated from these two frequency ranges differ by more than $30 \%$, which occurred $\sim 10 \%$ of the time over the entire cruise. Overall, $\sim 70 \%(584 \mathrm{~h})$ of sensible heat and momentum fluxes satisfy these criteria.

For OVOCs, to satisfy stationarity we omit periods when the hourly trends in methanol, acetone, and acetaldehyde exceeded than $0.2,0.1$, and $0.04 \mathrm{ppbh}^{-1}$, respectively, which occurred $\sim 10 \%$ of the time. In the cases of acetone and acetaldehyde, we also discard hours when the respective $\sigma$ exceeded 0.3 and $0.2 \mathrm{ppb}$ to limit the effect of contamination from the plastic funnel at the front of the intake. The number of hours that passes all of the requirements above is 484 , 310 , and 218 for methanol, acetone, and acetaldehyde, respectively.

\section{Results and discussion}

Figure 4 shows the latitudinal distributions of sea surface temperature (SST), air temperature $\left(T_{\mathrm{a}}\right)$, salinity, momentum flux $(\tau), 10 \mathrm{~m}$ neutral wind speed $\left(U_{10 \mathrm{~N}}\right)$, sensible heat flux $\left(Q_{\mathrm{H}}\right)$, and the sea-air temperature difference $(\Delta T)$. Scaled approximately to $U_{10 \mathrm{~N}}^{2}, \tau$ peaked during the high winds at $\sim 36^{\circ} \mathrm{N}$ and $\sim 33^{\circ} \mathrm{S}$. Sensible heat flux, in comparison, is a function of both $U_{10 \mathrm{~N}}$ and $\Delta T$. Within the intertropical convergence zone (ITCZ) where $\Delta T$ was large, $Q_{\mathrm{H}}$ remained low because of the weak winds. The Monin-Obukhov stability parameter $(z / L)$ from the Coupled Ocean-Atmosphere Response Experiment(COARE) model (Fairall et al., 2000) was negative for majority of the cruise, indicating an unstable 

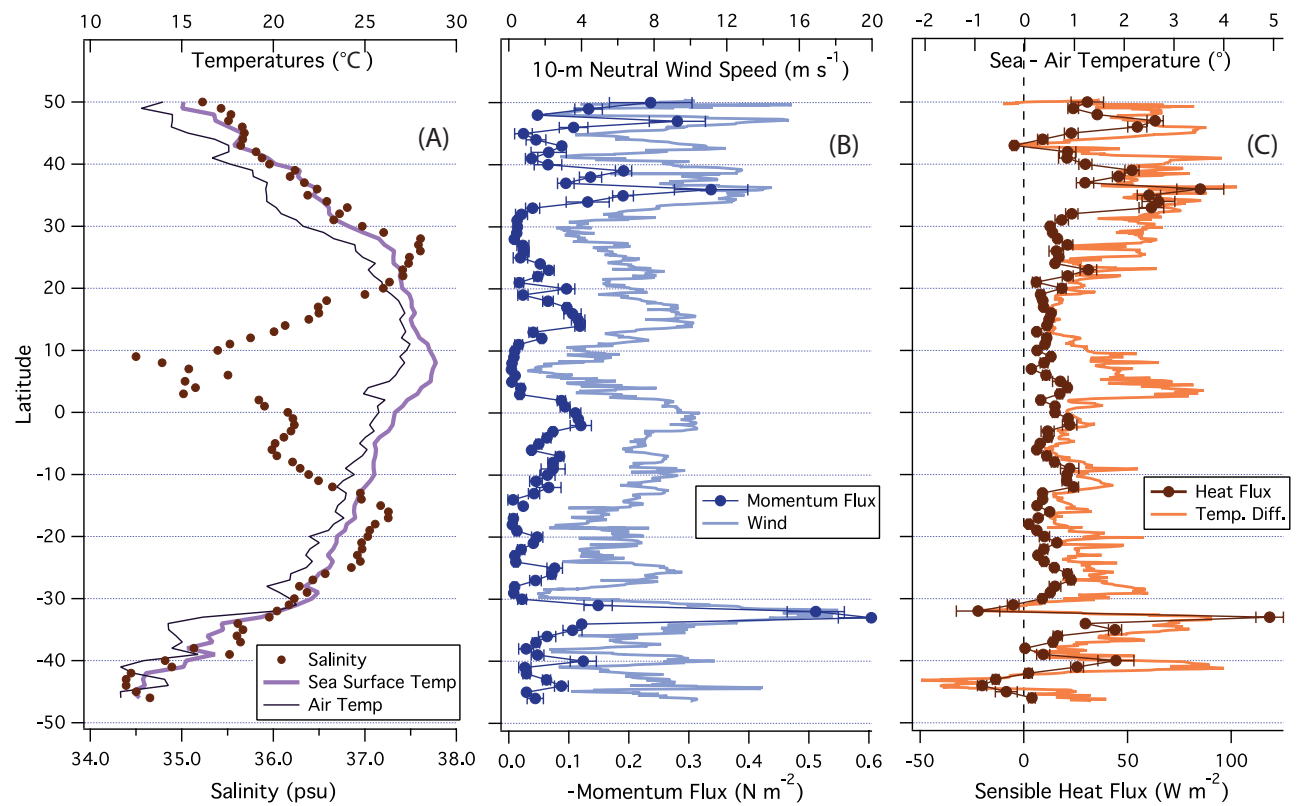

Figure 4. (A) Sea surface temperature, air temperature, and salinity (B) Wind speed and negative momentum flux; (C) Air-sea temperature difference and sensible heat flux. Sensible heat flux was usually from sea-to-air, except for short periods preceding storms near the beginning and end of the cruise. Error bars on fluxes correspond to standard errors.

atmosphere. In higher latitude regions and during short periods preceding storms, $z$ / $L$ became slightly positive (weakly stable), due to warm air from frontal passages advecting over cold water. We normalize the transfer velocities of heat $\left(k_{\text {heat }}=Q_{\mathrm{H}} / \Delta T\right)$ as well as methanol (Sect. 3.3) to neutral stability based on similarity theory (Fairall et al., 1996). This normalization assumes that heat and methanol have the same stability function $(\psi)$ as water vapor, which was computed from COARE.

Measured and predicted $k_{\text {heat }}$ values from COARE generally agree (Fig. 5). Three averaging schemes of the EC data are shown: hourly $Q_{\mathrm{H}}$ divided by hourly $\Delta T$, bin-average of hourly $k_{\text {heat }}$ according to wind speeds (error bars indicate 1 $\sigma$ ), and latitudinally averaged $Q_{\mathrm{H}}$ divided by latitudinally averaged $\Delta T$. There is no obvious bias between the latter two averaging methods, as would be expected from a relatively linear relationship of $k_{\text {heat }}$ with $U_{10 \mathrm{~N}}$. Compared to hourly data, reduction in scatter in the averaged results can be attributed to cancelation of random errors. As shown already by Yang et al. (2013b), the measured friction velocity, generally agrees with prediction from COARE. The consistencies in measured and modeled momentum/sensible transfer validate our motion correction.

Now we turn our attention to OVOCs. For comparison, we frequently refer to the works by Beale et al. (2013). They measured the seawater concentrations of methanol, acetone, and acetaldehyde along the same transect and during the same months in 2009 (AMT-19) using the identical PTRMS/membrane inlet system; they also estimated the air-sea OVOC fluxes based on modeled atmospheric concentrations.

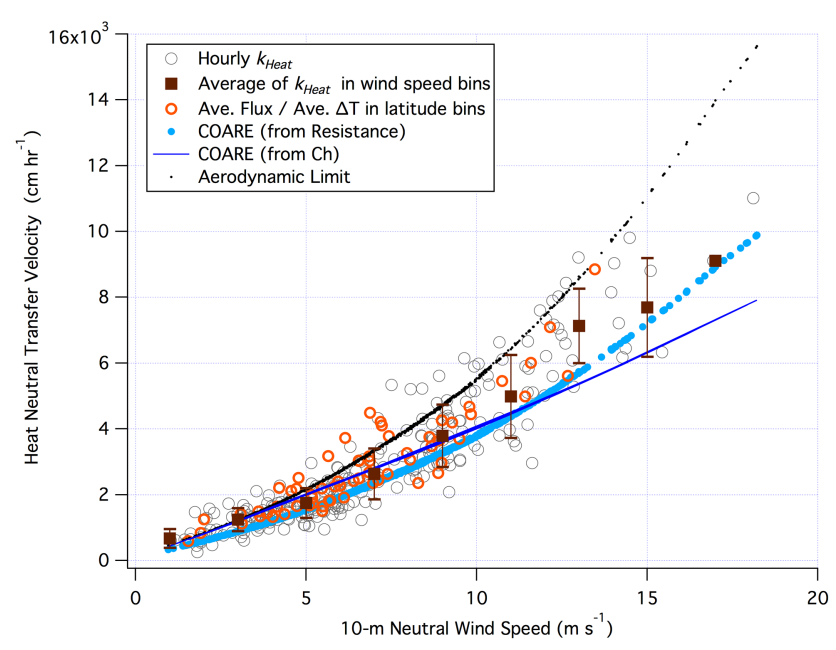

Figure 5. Measured heat transfer velocity vs. wind speed. Three approaches of data averaging are shown (see text for details). For clarity, only hours when $\Delta T>1{ }^{\circ} \mathrm{C}$ and relative wind direction between -30 and $100^{\circ}$ are shown. Error bars indicate standard deviations from the bin averages. Two parameterizations of heat transfer from the COARE model as well as the aerodynamic limit are also shown.

\subsection{Acetone}

Figure 6a shows the latitudinal distributions of acetone concentrations in air and in near-surface water. Displaying a distinctive hemispheric trend, atmospheric acetone concentrations were $\sim 0.6,0.4$, and $0.2 \mathrm{ppb}$ in the North, equatorial, 

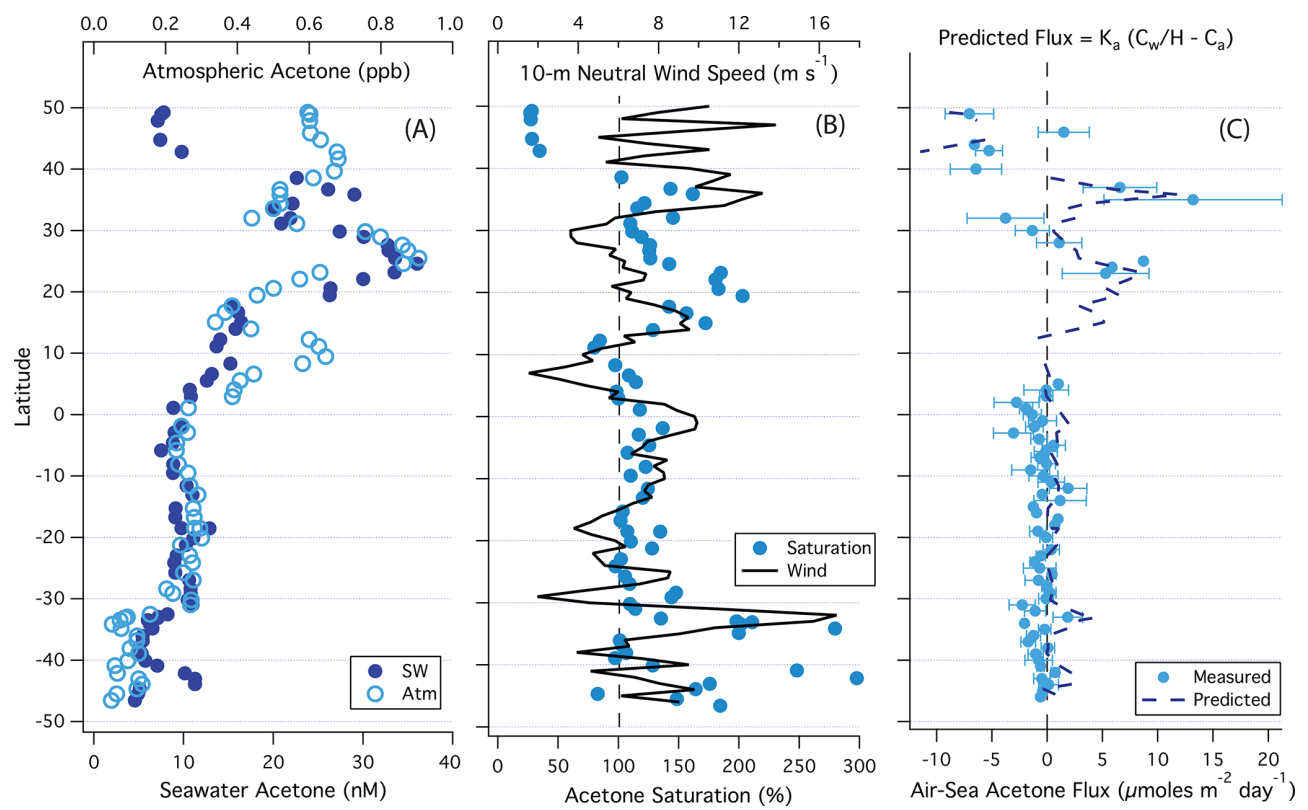

Figure 6. (A) Atmospheric and seawater ( $\sim 5 \mathrm{~m}$ depth) concentrations of acetone; (B) saturation of acetone and wind speed; (C) flux measured by EC and predicted with the two-layer model.

and South Atlantic, similar to previous measurements by Lewis et al. (2005), Williams et al. (2004), and Taddei et al. (2009), respectively. $C_{\text {a }}$ peaked in the subtropical North Atlantic at $\sim 0.9 \mathrm{ppb}$, within range of a 5 -year record at Cape Verde (Read et al., 2012) and shipboard observations by Marandino et al. (2005) in the Pacific at similar latitudes. With a mean value of $13.7 \mathrm{nM}$, dissolved acetone concentration is also comparable with previous open ocean observations (e.g. Williams et al., 2004; Marandino et al., 2005; Kameyama et al., 2010). In particular, latitudinal distribution of seawater acetone from AMT-22 shows remarkable similarity to measurements by Beale et al. (2013) during AMT-19.

Taddei et al. (2009) suggest enhanced acetone emission in regions of phytoplankton blooms based on highly uncertain flux measurements (in part due to a lack of motion correction on winds). Similar to Beale et al. (2013), we observed neither greater emission nor elevated seawater acetone concentration in biologically productive waters. Seawater acetone concentration peaked at $36 \mathrm{nM}$ in the oligotrophic North Atlantic subtropical gyre, where $\mathrm{Chl}_{\mathrm{a}}$ concentration was low $\left(<0.1 \mu \mathrm{g} \mathrm{L}^{-1}\right)$. South of $32^{\circ} \mathrm{S}, C_{\mathrm{w}}$ was only $\sim 5 \mathrm{nM}$ despite high biological productivity $\left(\mathrm{Chl}_{\mathrm{a}}>1 \mu \mathrm{g} \mathrm{L}{ }^{-1}\right)$. Photochemical destruction of dissolved organic matter (DOM) is thought to be a source of acetone (Kieber et al., 1990; Zhou and Mopper, 1997; Jacob et al., 2002; Dixon et al., 2013). Seawater acetone concentration measured from $500 \mathrm{~m}$ was typically $20-40 \%$ of $5 \mathrm{~m}$ value (Fig. 7), consistent with production predominantly in the photic layer. Similar depth profiles were observed by Williams et al. (2004) and Beale et al. (2013). Despite the expected photochemical source, seawater acetone concentrations from predawn and solar noon casts were statistically identical in our measurements. $C_{\mathrm{w}}$ also did not demonstrate a positive correlation with colored dissolved organic matter (CDOM) measured on this cruise (G. Tilstone, AMT-22 Cruise Report). Such light-driven effects might become more obvious closer to the surface (than $5 \mathrm{~m}$ ). While greater consumptions of OVOCs at depth could also explain the lower concentrations observed at $500 \mathrm{~m}$ than near the surface, works from Dixon et al. $(2012,2013)$ suggest that microbial oxidations of these compounds are generally slower in deep waters.

For most of the cruise, the atmospheric and seawater acetone concentrations followed relatively similar distributions. Significant deviations from equilibrium were observed north of $40^{\circ} \mathrm{N}$, where the surface ocean was undersaturated, and in the subtropical North Atlantic, where the ocean was supersaturated (Fig. 6b), in agreement with Beale et al. (2013). Calculated saturation levels were noisy south of $32^{\circ} \mathrm{S}$ partly due to low atmospheric concentrations ( $\sim 0.1 \mathrm{ppb})$. Interestingly, acetone was close to $100 \%$ saturation in the Southern Hemisphere, which suggests the oceanic production and consumption rates of this compound were strongly coupled and/or relatively slow in that region, such that air-sea exchange could maintain equilibrium. A slow removal rate would be consistent with the long oceanic lifetime of acetone (5-55 days) recently reported by Dixon et al. (2013).

Measured and predicted air-sea acetone fluxes are in broad agreement and consistent with saturation values, with net deposition in higher latitudes of the North Atlantic and emission in the subtropics (Fig. 6c). The saturation state and the sign of predicted net flux become more sensitive to the choice of solubility the closer the compound is to 


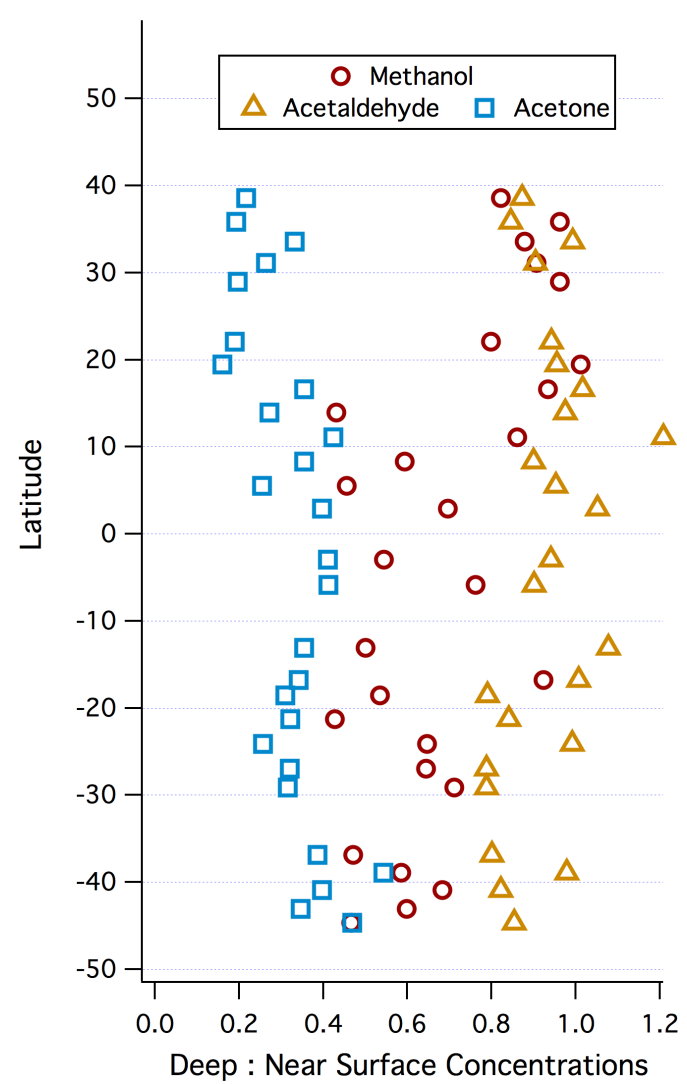

Figure 7. Ratios of seawater OVOC concentrations from depth (nominally $500 \mathrm{~m}$ ) to those from $\sim 5 \mathrm{~m}$. For methanol, this ratio was $\sim 0.8$ in the North Atlantic and $\sim 0.6$ elsewhere. For acetaldehyde, concentrations at depth were similar to concentrations near the surface. Acetone concentration showed the most reduction at depth, with a fraction ranging from $\sim 0.2$ in the subtropical North Atlantic to $\sim 0.4$ in the higher latitudes of the South Atlantic.

equilibrium. For example, from 12 to $3^{\circ} \mathrm{N}$, a mean acetone flux $-0.6 \mu$ moles $\mathrm{m}^{-2} \mathrm{~d}^{-1}$ is predicted using the solubility from Zhou and Mopper (1990). If the solubility from Benkelberg et al. (1995) is used instead, the predicted net flux becomes $1.0 \mu$ moles $\mathrm{m}^{-2} \mathrm{~d}^{-1}$. We also examine the sensitivity of the predicted net flux with respect to the choice of $k_{\mathrm{a}}$. For simplicity, if we take the measured methanol deposition velocity (Sect. 3.3) to be $k_{\mathrm{a}}$ for acetone, the magnitude of the predicted net acetone flux would be $\sim 10 \%$ higher than what is shown in the subtropical North Atlantic. Uncertainties in the acetone flux and atmospheric concentration were large in the North Atlantic due to the funnel contamination, while flux was near zero in the South Atlantic. Thus we are unable derive a reliable transfer velocity of acetone.

Over the entire transect, the emission and deposition fluxes of acetone largely cancel, resulting in mean EC flux (propagated uncertainty) of $-0.2(2.5) \mu$ moles $\mathrm{m}^{-2} \mathrm{~d}^{-1}$ and predicted net flux of $1.0(2.0) \mu$ moles $\mathrm{m}^{-2} \mathrm{~d}^{-1}$. Crudely extrapolating to the total area of the world oceans (assuming the same concentrations, wind speeds, temperatures, etc as during AMT-22), the net air-sea acetone transport inferred from EC and predicted fluxes is -1 (19) and 8 (15) $\mathrm{Tg} \mathrm{yr}^{-1}$, respectively. These estimates are similar in magnitude to modeled results from Jacob et al. (2002) and Fischer et al. (2012), as well as to the extrapolations by Beale et al. (2013). The EC acetone flux from Marandino et al. (2005) was always into the ocean; from that they estimated a much larger oceanic sink of acetone, which is comparable to our gross acetone deposition (see Sect. 3.4). If they had used their measured air/sea concentrations (which showed both undersaturation and supersaturation) to estimate the global air-sea flux, they likely would have arrived at a much smaller sink on average.

\subsection{Acetaldehyde}

Figure 8a shows the latitudinal distributions of acetaldehyde in air and near-surface water. Atmospheric acetaldehyde concentration averaged $\sim 0.18 \mathrm{ppb}$ in the Northern Hemisphere, within the range of previously measured values in the arboreal autumn (e.g. Lewis et al., 2005; Read et al., 2012). A peak in $C_{\mathrm{a}}$ at $\sim 10^{\circ} \mathrm{N}(\sim 0.25 \mathrm{ppb})$ mirrored the peaks in atmospheric acetone and methanol, in the outflow region of northern Africa. $C_{\mathrm{a}}$ was lower in the Southern Hemisphere, with an average of $\sim 0.08 \mathrm{ppb}$.

Seawater acetaldehyde were $\sim 9 \mathrm{nM}$ in the higher latitude North Atlantic and $\sim 4 \mathrm{nM}$ in the South Atlantic, within the range of previous seawater measurements (Mopper and Kieber, 1991; Zhou and Mopper, 1997; Beale et al., 2013). Zhou and Mopper (1997) reported enrichment in the microlayer of calm and presumably productive Florida waters and attributed it to photochemical production. Exposing natural waters to sunlight, Kieber et al. (1990) found a strong relationship between acetaldehyde production and CDOM absorbance, which was later used by Millet et al. (2010) to predict global acetaldehyde emission. In our data, statistically there was no difference between noon $(5.5 \pm 1.7 \mathrm{nM})$ and predawn $(5.2 \pm 1.7 \mathrm{nM})$ values for near surface acetaldehyde, similar to the findings by Beale et al. (2013). As with acetone, seawater acetaldehyde concentration did not demonstrate a positive relationship with CDOM (G. Tilstone, AMT22 Cruise Report). Furthermore, concentration at $\sim 500 \mathrm{~m}$ was similar to the near surface (Fig. 7), consistent with depth profiles observed by Mopper and Kieber (1991) in the Black Sea and Beale et al. (2013) from AMT-19. The absences of a significant diel cycle as well as a vertical gradient could be due to the very fast (lifetime $<1 \mathrm{~d}$ ) microbial consumption of acetaldehyde (Dixon et al., 2013).

Acetaldehyde appears to be significantly supersaturated in seawater (average of $\sim 300 \%$, Fig. $8 b$ ) relative to the atmosphere across the Atlantic, implying consistent emission. Dissolved acetaldehyde exists in equilibrium with the hydrate 1,1-ethanediol, $\mathrm{CH}_{3} \mathrm{CH}(\mathrm{OH})_{2}$, with a hydration constant $(\varepsilon)$ of $\sim 1.4$ (Bell and Avans, 1966). Only the unhydrated form is volatile and directly subject to air-sea 

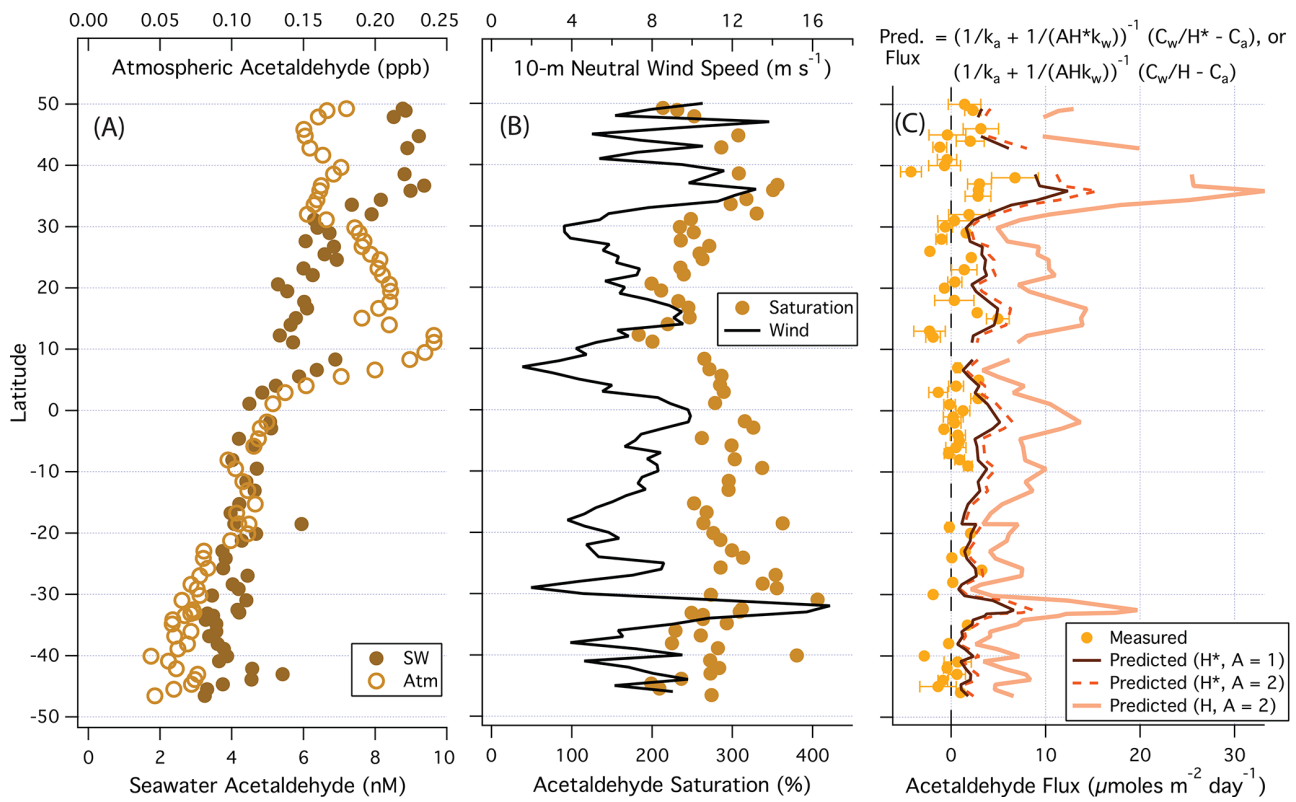

Figure 8. (A) Atmospheric and seawater ( $\sim 5 \mathrm{~m}$ depth) concentrations of acetaldehyde; (B) saturation of acetaldehyde and wind speed; (C) flux measured by EC and predicted with the two-layer model with three different considerations of hydration/chemical enhancement.

exchange. Since our measurements are calibrated using aqueous standards diluted from pure acetaldehyde, they represent total concentration in water $\left(\mathrm{CH}_{3} \mathrm{CHO}+\mathrm{CH}_{3} \mathrm{CH}(\mathrm{OH})_{2}\right)$. Due to the relatively rapid reversible hydration/dehydration rate (on the order of $\sim 0.1 \mathrm{~s}^{-1}$ at $25^{\circ} \mathrm{C}$ and a $\mathrm{pH}$ of 8.1 ; Bell et al., 1956; Kurz and Coburn, 1967), solubility of acetaldehyde reported in the literature is usually the apparent solubility $\left(H^{*}\right)$, or the ratio between total dissolved acetaldehyde and the gas phase concentration. $H^{*}$ is related by the factor of $1 /(1+\varepsilon)$ to the intrinsic Henry's solubility $(H)$ between dissolved $\mathrm{CH}_{3} \mathrm{CHO}$ and the gaseous constituent. The hydration reaction increases the effective rate of aqueous diffusion $(D)$, and so reduces waterside resistance in airsea transfer. Using $\varepsilon$ from Bell and Avans (1966), hydration rate from Schecker and Schultz (1969), and the thickness of the aqueous diffusive sub-layer $\left(D / k_{\mathrm{w}}\right)$, Zhou and Mopper (1997) estimated a chemical enhancement factor $(A)$ of 2 for acetaldehyde using the model from Hoover and Berkshire (1969).

$\mathrm{v}$ We calculate acetaldehyde flux following Eqs. (A1) and (A2), but with $H^{*}$ in place of $H$. A is set to 1 (no enhancement, e.g. Beale et al., 2013) as well as 2 (with enhancement, e.g. Millet et al., 2010). Flux is increased by $\sim 20 \%$ in the latter case. This relative insensitivity is due to the substantial airside resistance for acetaldehyde. The chemical enhancement of acetaldehyde over the open ocean may be smaller still. Following Hoover and Berkshire (1969), A approaches 2 only with a very rapid hydration rate $\left(\sim 3 \mathrm{~s}^{-1}\right)$ and at wind speeds of $\sim 2 \mathrm{~m} \mathrm{~s}^{-1}$; at $10 \mathrm{~m} \mathrm{~s}^{-1}$ winds, $A$ is reduced to $\sim 1.4$. With a slower hydration rate of $\sim 0.1 \mathrm{~s}^{-1}$, $A$ is only $\sim 1.1$ in moderate winds. We note that using the in-

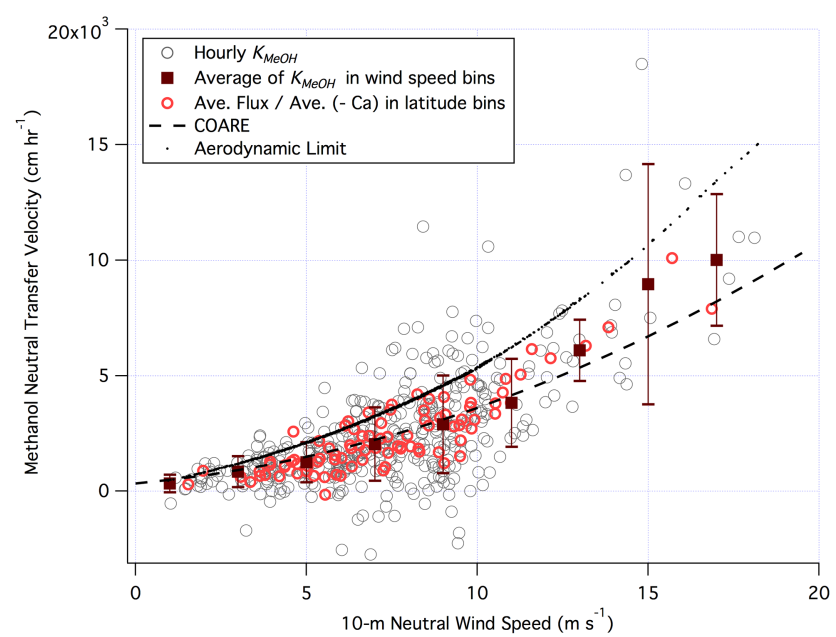

Figure 9. Transfer velocity of methanol calculated with a purely depositional approach vs. wind speed. Three types of averaging are shown (see text for details). Error bars correspond to standard deviations from the bin averages. The aerodynamic limit describes the rate of turbulent transfer in the atmosphere.

trinsic Henry's solubility $H$ and the total seawater acetaldehyde concentration in the flux estimation is incorrect because $C_{\mathrm{a}} \neq C_{\mathrm{w}} / H$ and $C_{\mathrm{a}, 0} \neq C_{\mathrm{w}, 0} / H$. As shown in Fig. 8c, doing so overestimates acetaldehyde flux by about a factor of 3.

With $A=1$ the predicted net acetaldehyde flux (propagated error) is $\sim 3.2(1.1) \mu$ moles $\mathrm{m}^{-2} \mathrm{~d}^{-1}$, while the EC flux is $\sim 0.6(2.5) \mu$ moles $\mathrm{m}^{-2} \mathrm{~d}^{-1}$ for the entire transect. With $A>1$, the discrepancy between measured and predicted 


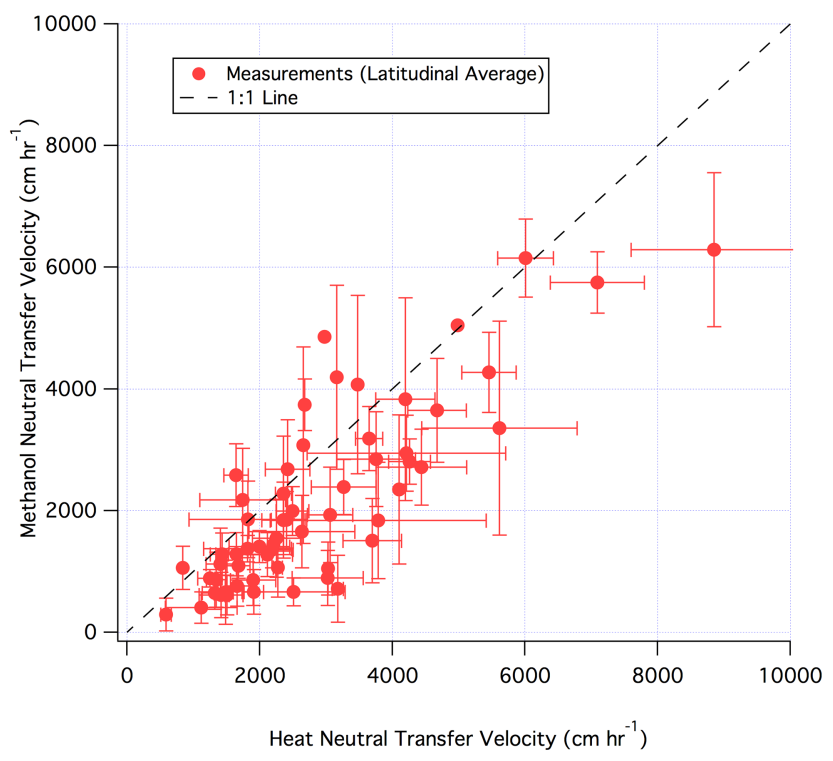

Figure 10. Methanol transfer velocity vs. heat transfer velocity in latitudinal bins (error bars indicate standard errors). Methanol transfer velocity was $\sim 85 \%$ of the heat transfer velocity, consistent with the lower diffusivity (higher Schmidt number) of methanol than heat in air.

fluxes would be even greater. While within the range of measurement uncertainties, the EC flux appears to be lower than predicted possibly because the signal was close to the system's detection limit $\left(4 \mu\right.$ moles $\mathrm{m}^{-2} \mathrm{~d}^{-1}$ hourly and $2 \mu$ moles $\mathrm{m}^{-2} \mathrm{~d}^{-1}$ latitudinally averaged; see Appendix C) and thus not well resolved. The predicted net flux could also be in error due to unknown biases in $C_{\mathrm{w}}$ and/or $C_{\mathrm{a}}$. Decreasing $C_{\mathrm{w}}$ by $\sim 2.5 \mathrm{nM}$ or increasing $C_{\mathrm{a}}$ by $\sim 0.15 \mathrm{ppb}$ would bring predicted fluxes $(A=1)$ inline with observations. Crudely extrapolating EC and predicted net acetaldehyde fluxes from the AMT-22 to the world oceans results in a global air-sea transport of 3 (14) and 18 (6) $\mathrm{Tg} \mathrm{yr}^{-1}$, which are of the same order of magnitude as the estimate from Beale et al. (2013). Our EC measurements suggest that the "actual" acetaldehyde emission is unlikely to be much higher (e.g. if chemical enhancement were substantial), for otherwise it would have been more clearly detected. As with acetone, we could not derive the transfer velocity of acetaldehyde due to the large uncertainties. Future efforts on quantifying $K_{\mathrm{a}}$ of OVOCs should probably focus on the Northern Hemisphere where the flux signals and concentrations are large.

\subsection{Methanol}

As shown already by Yang et al. (2013b), the air-sea transfer velocity of methanol $\left(K_{\mathrm{MeOH}}\right)$ appears to resemble pure deposition (i.e. Flux $\approx-K_{\mathrm{MeOH}} C_{\mathrm{a}}$ ). As with $k_{\text {heat }}$, we use three different averaging approaches in the calculation of $K_{\mathrm{MeOH}}$ (=Flux/- $C_{\mathrm{a}}$ ) (Fig. 9): hourly flux divided by hourly $\left(-C_{\mathrm{a}}\right)$,
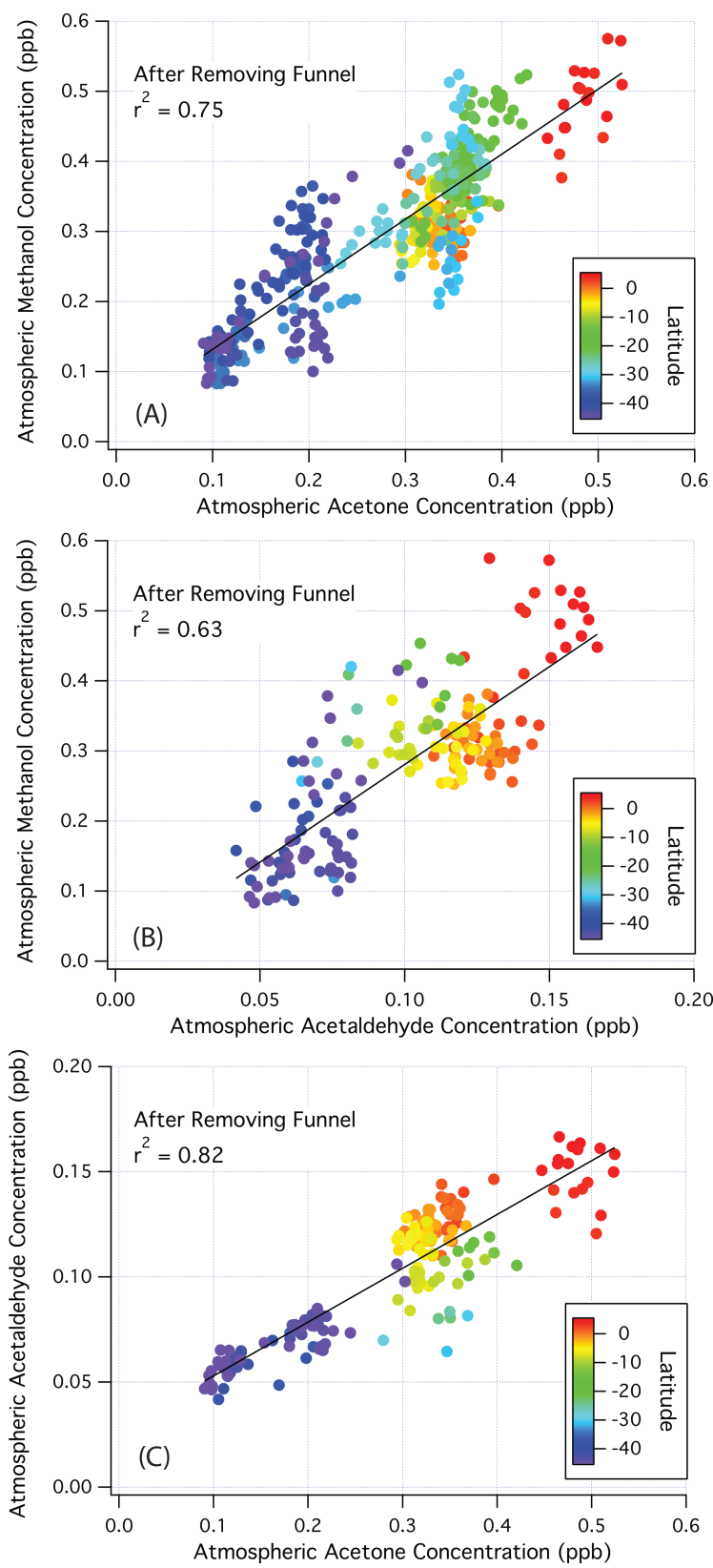

Figure 11. Atmospheric concentrations of (A) methanol vs. acetone, (B) methanol vs. acetaldehyde (B), and (C) acetaldehyde vs. acetone after the removal of the inlet funnel, color-coded by latitude. The high degrees of positive correlations between these compounds and their similar latitudinal distributions imply that they share some common sources and sinks.

bin-average of hourly $K_{\mathrm{MeOH}}$ according to wind speed (error bars correspond to $1 \sigma$ ), and latitudinally averaged flux divided by latitudinally averaged $\left(-C_{\mathrm{a}}\right)$. Also shown is the estimate from the COARE model, which compares well with measurements up to wind speeds of $\sim 10 \mathrm{~m} \mathrm{~s}^{-1}$. Above those winds, our limited number of measurements are 10-20\% higher than the COARE model. We can further examine the 

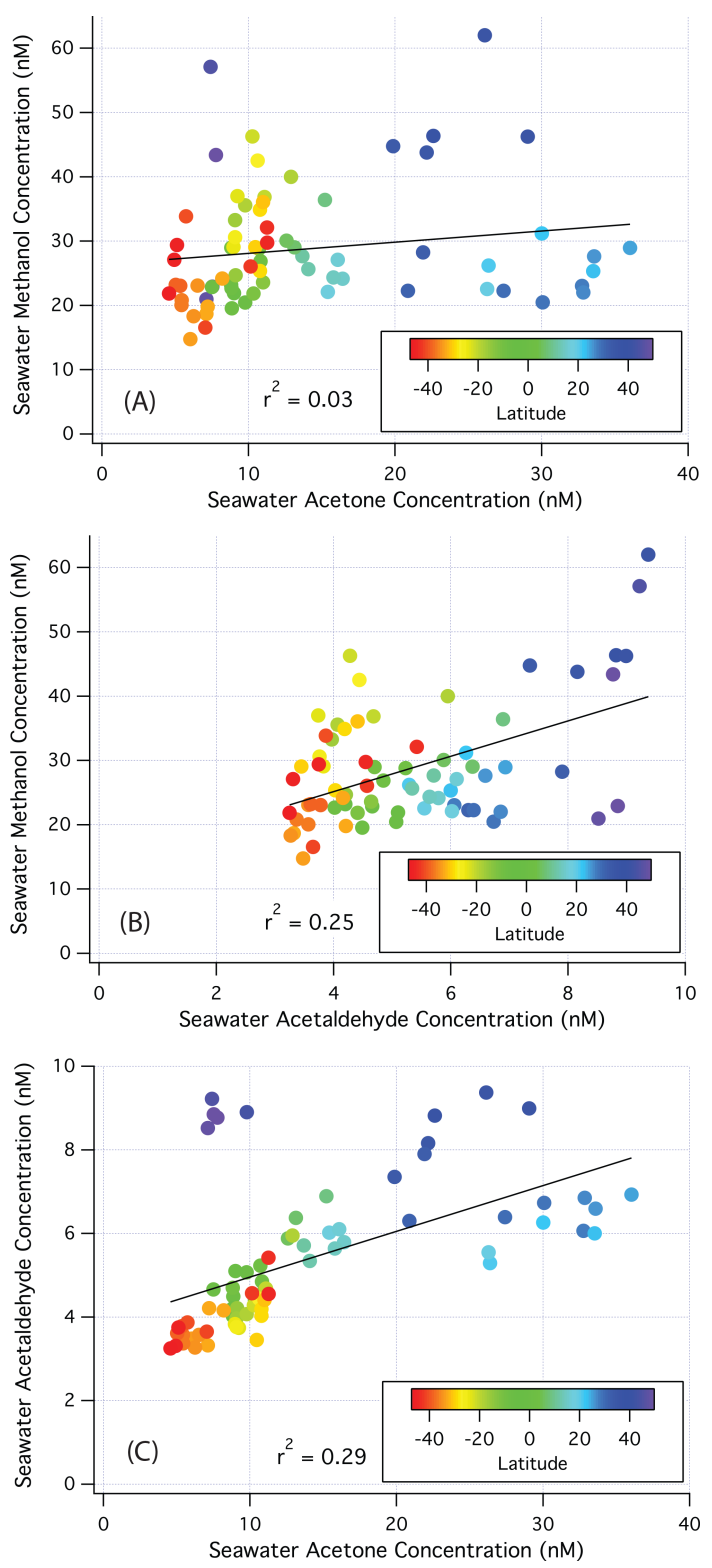

Figure 12. Near surface seawater concentrations of (A) methanol vs. acetone, (B) methanol vs. acetaldehyde (B), and (C) acetaldehyde vs. acetone, color-coded by latitude. Correlations between seawater concentrations are much lower than those between air concentrations, implying different oceanic production and consumption pathways of these compounds.

validity of $K_{\mathrm{MeOH}}\left(=\right.$ Flux $\left./-C_{\mathrm{a}}\right)$ by comparing it to $k_{\text {heat }}$ (Fig. 10). $K_{\mathrm{MeOH}}$ is about $15 \%$ lower than $k_{\text {heat }}\left(r^{2}=0.7\right)$, consistent with the higher $\mathrm{Sc}_{\mathrm{a}}$ for methanol (1.09) than heat (0.64). Using $R_{\mathrm{m}}$ from COARE and from Hicks et al. (1986), the predicted ratio between these two transfer velocities is about 0.90 and 0.92 , respectively. If the measured waterside concentration $C_{\mathrm{w}}$ were used in the $K_{\mathrm{MeOH}}$ calculation instead, the resultant $K_{\mathrm{MeOH}}$ would significantly exceed $k_{\text {heat }}$, as discussed in detail by Yang et al. (2013b).
The seawater methanol concentrations of $15-62 \mathrm{nM}$ from AMT-22 are lower than previous observations (e.g. 48$361 \mathrm{nM}$ during AMT-19 by Beale et al., 2013; about $60-230 \mathrm{nM}$ by Williams et al., 2004 in the tropical Atlantic) for reasons currently unknown. Incubation experiments during AMT-19 (Dixon et al., 2013) suggest significant in situ production and consumption of seawater methanol along the transect (net change ranging from -428 to $+89 \mathrm{nmol} \mathrm{L}^{-1} \mathrm{~d}^{-1}$ ). While primary production rates were lower during AMT-22 than during AMT-19 (G. Tilstone, AMT-22 Cruise Report), a direct linkage between phytoplankton activities and seawater methanol concentration has not been demonstrated. The ratio between dissolved methanol concentrations at $\sim 500 \mathrm{~m}$ and $\sim 5 \mathrm{~m}$ was $\sim 0.8$ in the higher latitudes of the North Atlantic and $\sim 0.6$ elsewhere (Fig. 7), proportionally similar to depth profiles measured previously by Williams et al. (2004) and Beale et al. (2013). Heikes et al. (2002) speculated the phytoplankton metabolite dimethylsulfoniopropionate (DMSP) to be a precursor of marine methanol. Near surface methanol concentrations from AMT-22 as well as AMT-19 (Beale et al., 2013) do not follow previously measured trends of DMSP on AMT transects, which show enhancement in productive waters relative to the oligotrophic gyres (Bell et al., 2010). At $\sim 500 \mathrm{~m}$, DMSP concentration should be essentially zero. Thus the source of dissolved methanol does not appear to be limited in the photic zone, which is consistent with a lack of diel difference in seawater methanol concentration during AMT-22 and also with the results from incubation experiments by Dixon et al. (2013).

\subsection{Relationships between OVOCs and gross air-sea fluxes}

We examine the relationships between the atmospheric OVOC concentrations south of $5^{\circ} \mathrm{N}$, after the removal of the plastic funnel (Fig. 11). The high degrees of positive correlations between these compounds and their similar latitudinal distributions imply common sources and sinks in the atmosphere (e.g. terrestrial emissions, photochemistry). In contrast, the relationships between OVOC concentrations are much weaker in the surface water (Fig. 12). Separating the seawater OVOC concentrations into different oceanic provinces, we see some significant correlations $(95 \%$ confidence) in the tropical Atlantic $\left(15^{\circ} \mathrm{N}\right.$ to $\left.7^{\circ} \mathrm{S}, n=13\right)$ : $r^{2}=0.42$ (methanol vs. acetone), 0.67 (methanol vs. acetaldehyde), and 0.64 (acetone vs. acetaldehyde), as well as in the south subtropical convergence ( 30 to $47^{\circ} \mathrm{S}, n=20$ ): $r^{2}=0.26$ (methanol vs. acetone), 0.31 (methanol vs. acetaldehyde), and 0.56 (acetone vs. acetaldehyde). However, in general the seawater OVOC concentrations are not significantly correlated with available environmental variables (e.g. chlorophyll a, CDOM, SST, $\mathrm{O}_{2}$ ) even when segregated by region. This suggests that the oceanic budgets of these compounds may be dictated by different processes, such as 
Table 1. Summary of fluxes ( $\mu$ moles $\mathrm{m}^{-2} \mathrm{~d}^{-1}$ ) and associated uncertainties in parenthesis.

\begin{tabular}{lrrrr}
\hline & EC flux & Predicted net flux & Gross deposition & Gross emission \\
\hline $50-40^{\circ} \mathrm{N}$ & & & & \\
Acetone & $-4.8(3.5)$ & $-7.8(3.3)$ & $-11.1(4.4)$ & $3.3(1.2)$ \\
Acetaldehyde & $0.8(3.1)$ & $3.9(2.0)$ & $-2.7(1.0)$ & $6.6(2.3)$ \\
Methanol & $-12.3(3.9)$ & $-10.5(2.9)$ & $-12.8(2.9)$ & $2.3(1.0)$ \\
$39-3^{\circ} \mathrm{N}$ & & & & \\
Acetone & $3.3(3.2)$ & $3.0(3.2)$ & $-8.8(3.2)$ & $11.8(4.2)$ \\
Acetaldehyde & $0.9(2.4)$ & $4.0(1.5)$ & $-2.5(0.9)$ & $6.5(2.4)$ \\
Methanol & $-12.7(3.1)$ & $-9.2(2.6)$ & $-12.3(2.7)$ & $3.1(1.4)$ \\
$2^{\circ} \mathrm{N}-47^{\circ} \mathrm{S}$ & & & & \\
Acetone & $-0.5(2.3)$ & $1.0(1.1)$ & $-3.4(1.2)$ & $4.4(1.0)$ \\
Acetaldehyde & $0.4(2.1)$ & $2.4(1.0)$ & $-1.5(0.5)$ & $3.9(1.4)$ \\
Methanol & $-8.0(2.6)$ & $-4.3(1.4)$ & $-6.5(1.5)$ & $2.2(1.0)$ \\
\hline
\end{tabular}

Uncertainty in EC flux estimated following Blomquist et al. (2010). Uncertainty in predicted/bulk fluxes propagated from the following uncertainties ( $\sim 95 \%$ confidence level): $20 \%$ for airside and waterside transfer velocities; $20 \%$ for solubility; 20, 20, $10 \%$ for atmospheric concentrations of acetone, acetaldehyde, and methanol, respectively; 10,10 , $30 \%$ for seawater concentrations of these compounds.
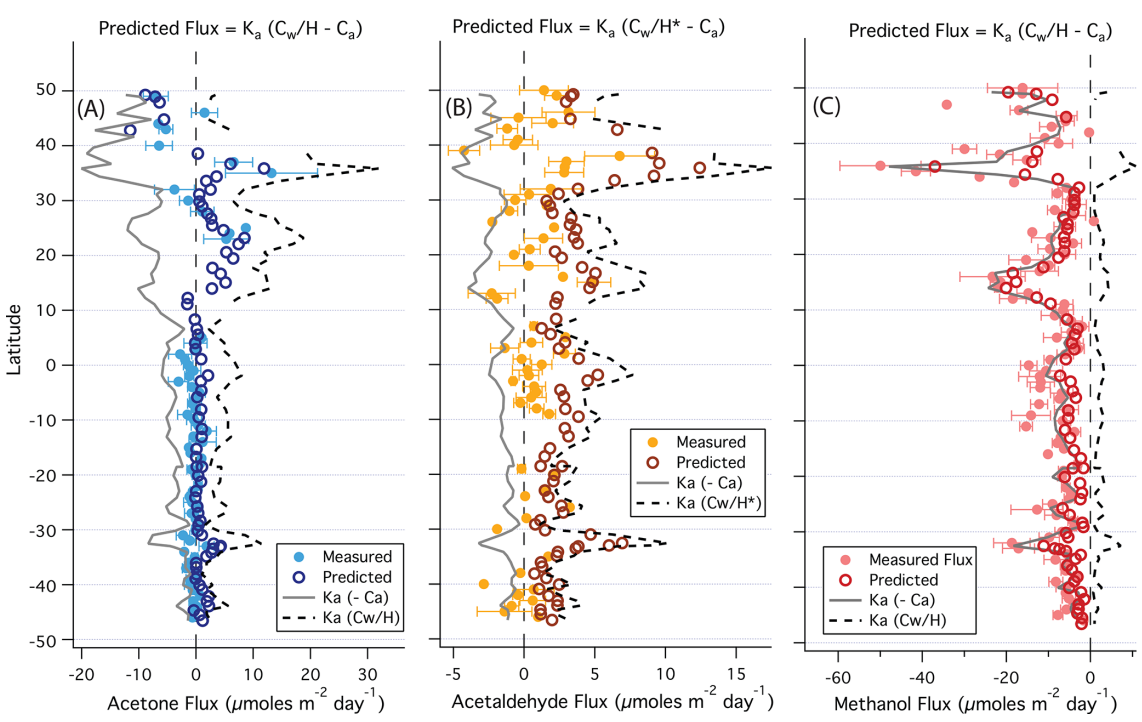

Figure 13. Measured as well as predicted net (difference between emission and deposition) and gross (total emission and deposition) fluxes for acetone, acetaldehyde, and methanol.

biological activities, photochemistry, atmospheric input, etc., the relative importance of which probably vary from compound to compound.

Methanol, acetone, and acetaldehyde together constitute a large fraction of total organics in the background marine atmosphere. How important are they in carbon cycling? In global OVOC models (e.g. Jacob et al., 2002; Heikes et al., 2002; Millet et al., 2008), air-sea transport is often separated into gross emission and deposition terms. Even if the net airsea flux is near zero, there can still be substantial transport of OVOC molecules from one reservoir to the other (depending on the concentrations). The specification of gross fluxes helps to distinguish between different OVOC sources in the ocean and the atmosphere. In Fig. 13 , by setting $C_{\mathrm{a}}$ and $C_{\mathrm{w}}$ to zero, we calculate the gross emission and deposition fluxes for acetone, acetaldehyde, and methanol. The EC flux should lie within the bounds of the gross fluxes provided that the air/water concentrations and $K_{\mathrm{a}}$ are reasonable. The net and gross fluxes are summarized in Table 1 for the two hemispheres (divided by the ITCZ); the latitude band of $40-50^{\circ} \mathrm{N}$ is presented separately to illustrate the sign change in net acetone flux.

For acetone, gross emission (mean of 7.1 umoles $\mathrm{m}^{-2} \mathrm{~d}^{-1}$, $54 \mathrm{Tg} \mathrm{yr}^{-1}$ globally) and deposition (mean of $-6.3 \mu$ moles $\mathrm{m}^{-2} \mathrm{~d}^{-1}, \quad-48 \mathrm{Tg} \mathrm{yr}^{-1}$ globally) mirror each other for most of the cruise track; the magnitudes of both terms are reduced in the South Atlantic, resulting in near zero net transport. For acetaldehyde, the predicted gross 
emission (mean of $5.1 \mu$ moles $\mathrm{m}^{-2} \mathrm{~d}^{-1}, 29 \mathrm{Tg} \mathrm{yr}^{-1}$ globally) exceeds deposition (mean of $-1.9 \mu$ moles $\mathrm{m}^{-2} \mathrm{~d}^{-1}$, $-11 \mathrm{Tg} \mathrm{yr}^{-1}$ globally), implying net emission. In the case of methanol, we use the measured $K_{\mathrm{a}}\left(=\right.$ Flux $\left./-C_{\mathrm{a}}\right)$ from Yang et al. (2013b) instead of the predicted transfer velocity from the COARE model. Because of the low saturations of methanol (on average $\sim 30 \%$ ), the net methanol flux is fairly similar to the gross deposition flux, while the gross emission is small. Over the entire transect, the gross emissions and depositions of the three OVOCs sum up to be 15 and $-18 \mu$ moles $\mathrm{m}^{-2} \mathrm{~d}^{-1}$ (94 and $-101 \mathrm{Tg} \mathrm{yr}^{-1}$ globally). These are $\sim 3$ orders of magnitude smaller than the net air-sea gaseous TOC flux estimated by Dachs et al. (2005) in the southeast subtropical Atlantic, an area influenced by African outflow. To answer the question of whether a substantial fraction of organic carbon is missing from the current species-specific air-sea transfer estimates, a closure of the TOC flux is urgently required.

\section{Conclusion}

On a trans-Atlantic cruise in 2012, we measured the air-sea fluxes of methanol, acetone, and acetaldehyde using a PTRMS with the EC technique. We also measured their near surface concentrations, enabling a comparison between fluxes directly measured and predicted by the two-layer model. In the North Atlantic, the higher latitude waters represented a sink for acetone, while the subtropical gyre appeared to be a source. In the South Atlantic, measured acetone flux was near zero, as expected from the $\sim 100 \%$ saturation in the surface water. For acetaldehyde, with consideration of the hydration reaction a small net emission is predicted by the two-layer model, which was not well resolved by EC. The transfer velocity of methanol correlates linearly with that of sensible heat, consistent with predominant airside control. Strong positive correlations were found between the atmospheric concentrations of methanol, acetone, and acetaldehyde, suggesting similar sources and sinks of these compounds in air. Correlations between their seawater concentrations were much weaker, however, implying different oceanic production and destruction pathways. Finally, we quantified the gross air-sea fluxes of these compounds. 

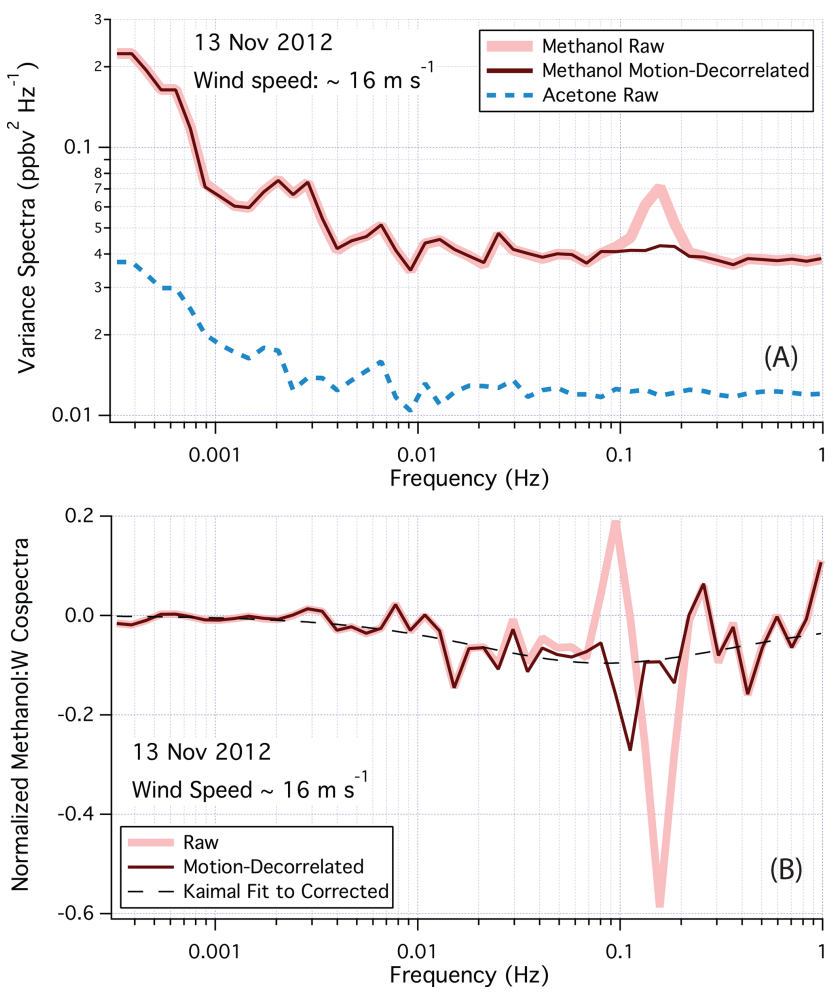

Figure A1. (A) Variance spectra of methanol (raw and motiondecorrelated) and acetone (raw) averaged over $10 \mathrm{~h}$ on a day of very high winds and severe motion; (B) cospectra of methanol:w (raw and motion-decorrelated) on this date. Decorrelation effectively removes the artificial peak in the raw methanol variance spectrum at the frequency of ship's motion $(0.08-0.2 \mathrm{~Hz})$, while preserving the spectrum elsewhere. The corrected methanol cospectrum is reasonably described by a Kaimal fit.

\section{Appendix A: Air-sea flux prediction}

We predict net air-sea flux from the two-layer model (Liss and Slater, 1974):

Flux $\approx K_{\mathrm{a}}\left(C_{\mathrm{w}} / H-C_{\mathrm{a}}\right) \approx K_{\mathrm{w}}\left(C_{\mathrm{w}}-H C_{\mathrm{a}}\right)$.

The total gas transfer velocity can be represented from the perspective of air concentration $\left(K_{\mathrm{a}}\right)$ as well as water concentration $\left(K_{\mathrm{w}}\right)$, which are related by the dimensionless liquid to gas solubility $H: K_{\mathrm{a}}=H K_{\mathrm{w}} . C_{\mathrm{w}}$ and $C_{\mathrm{a}}$ are the concentrations of the gas in water and air. Assuming equilibrium at the boundary between the two phases, $C_{\mathrm{w}} / H$ and $H C_{\mathrm{a}}$ are estimates of the interfacial concentrations on the airside and waterside, which are not measurable in practice. Thus from either perspective in Eq. (A1), zero concentration gradient is explicitly assumed in the other phase, which could bias the predicted flux.

The total gas transfer velocity is partitioned to individual transfer velocities in the two phases ( $k_{\mathrm{a}}$ and $k_{\mathrm{w}}$, respectively):

$K_{\mathrm{a}}=1 /\left(1 / k_{\mathrm{a}}+1 /\left(\mathrm{A} H k_{\mathrm{w}}\right)\right)$.
The term $A$ accounts for chemical enhancement in waterside transfer due to aqueous hydration/reactions; $A$ is assumed to be unity nonreactive gases such as methanol and acetone and has previously been estimated to be 2 for acetaldehyde due to hydration (see Sect. 3.2). Unlike sparingly soluble gases that are limited on the waterside (i.e. $K_{\mathrm{w}} \approx k_{\mathrm{w}}$ ), the exchange of highly soluble gases, such as methanol, is limited on the airside (i.e. $K_{\mathrm{a}} \approx k_{\mathrm{a}}$ ). For gases with intermediate solubility, such as acetone and acetaldehyde, resistances on the airside and the waterside are of similar magnitude such that the predicted net flux is subject to combined uncertainties in $k_{\mathrm{a}}$ and $k_{\mathrm{w}}$.

Unless otherwise specified, we use $k_{\mathrm{a}}$ and $k_{\mathrm{w}}$ from the COARE Gas Transfer model (Fairall et al., 2011) in the flux prediction. COARE accounts for turbulent and molecular diffusive resistance on the airside:

$k_{\mathrm{a}}=u_{*} /\left(R_{t}+R_{\mathrm{m}}\right)$

The dimensionless turbulent (aerodynamic) resistance $\left(R_{t}\right)$ is approximately equal to $U / u_{*}$. The molecular diffusive resistance is represented by $R_{\mathrm{m}}=13.3 \mathrm{Sc}_{\mathrm{a}}^{1 / 2}$, where $\mathrm{Sc}_{\mathrm{a}}$ is the airside Schmidt number. In comparison, $R_{\mathrm{m}}=5 \mathrm{Sc}_{\mathrm{a}}^{2 / 3}$ from Hicks et al. (1986) is used in the parameterization of Duce et al. (1991). The waterside and airside Schmidt numbers are taken from Johnson (2010). To estimate $k_{\mathrm{w}}$, the empirical constants for direct and bubble-mediated gas transfer are set to 1.3 (Blomquist et al., 2006) and 0 (due to the relatively high solubility of OVOCs, Woolf 1997), respectively. In the predictions of sensible heat and water vapor transfer, fits to historical measurements of dimensionless transfer coefficients $\left(C_{\mathrm{h}}\right.$ and $\left.C_{\mathrm{e}}\right)$ are used in COARE (e.g. $\left.k_{\text {heat }}=C_{\mathrm{h}} U\right)$.

A survey of published solubility values (Sander 1999) suggests uncertainties of $10-20 \%$ at $25^{\circ} \mathrm{C}$ for OVOCs; additional uncertainties exist in the temperature and salinity dependence of solubility. For acetone and acetaldehyde, we use the solubility measured in seawater by Zhou and Mopper (1990). For the latter, the reported value includes aqueous hydration. For methanol, we use the solubility in freshwater from Snider and Dawson (1985) and neglect its weak salinity dependence owning to the small molecular size (Johnson 2010). To relate the airside and waterside, latitudinally averaged atmospheric measurements are linearly interpolated to the times of water collection.

\section{Appendix B: OVOC Backgrounds}

Backgrounds for OVOC air measurements $\left(b_{k g d} d_{\text {air }}\right)$ were quantified by directing ambient air through a platinum catalytic converter (Shimadzu) for $2 \mathrm{~min}$ at the beginning of every hour. Heated to $350^{\circ} \mathrm{C}$, the converter should oxidize organic compounds to $\mathrm{CO}_{2}$ but not significantly alter the oxygen and water signals. At about $0.076 \%$ of the $\mathrm{O}_{2}^{+}$, the oxygen isotope $\left({ }^{16} \mathrm{O}^{17} \mathrm{O}^{+}\right)$accounted for about half of the $\mathrm{m} / \mathrm{z} 33$ background in air measurements. As documented 
by Beale et al. (2011), the seawater backgrounds $\left(\right.$ bkgd $\left._{\text {water }}\right)$ were taken to be the PTR-MS signal when measuring the carrier flow (high purity nitrogen gas passing through a separate but identical catalytic converter) that bypasses the silicone membrane.

For acetone, bkgd $_{\text {air }}$ and $\operatorname{bkgd}_{\text {water }}$ were within $\sim 10 \%$, implying a high efficiency of the catalyst at removing this compound. For methanol, the two backgrounds were also similar after accounting for the contribution of ${ }^{16} \mathrm{O}^{17} \mathrm{O}^{+}$in air. For acetaldehyde, however, $b_{k g d} d_{\text {air }}$ was $0.03-0.15 \mathrm{ppb}$

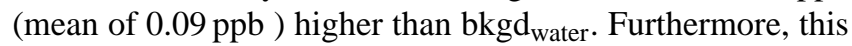
discrepancy became greater when the atmospheric acetaldehyde concentration was higher, implying that the catalyst was less efficient at removing $\mathrm{m} / \mathrm{z} 45$. We thus use bkgd $\mathrm{water}_{\text {to }}$ calculate the atmospheric acetaldehyde concentrations. This analysis suggests that the nighttime atmospheric acetaldehyde concentrations reported by Yang et al. (2013a) at a coastal site, which were computed based on bkgd ${ }_{\text {air }}$, may be underestimated by $\sim 0.1 \mathrm{ppb}$. Atmospheric ozone concentration measured on this cruise (S. Hackenberg, personal communication, 2012) did not correlate with acetaldehyde.

\section{Appendix C: OVOC Flux detection limits and uncertainties}

Uncertainty in OVOC flux measurements is a function of both random noise and natural variance in the chemical signal (Blomquist et al., 2010). We estimate the hourly detection limit as $3 \sigma$ of the covariance at an implausible lag time between OVOC and $w(+15 \mathrm{~s})$ during periods of fairly steady winds and OVOC concentrations. Over $16 \mathrm{~h}$ from 31 October to 1 November, with a wind speed of $\sim 10 \mathrm{~m} \mathrm{~s}^{-1}$, the hourly detection limits were $\sim 10,4$, and $5 \mu$ moles $\mathrm{m}^{-2} \mathrm{~d}^{-1}$ for methanol, acetaldehyde, and acetone. Random uncertainty in the EC flux are reduced by averaging to onedegree latitude bins $\left(\propto \mathrm{n}^{-1 / 2}\right.$, where $n$ is the number of independent measurements). At a ship speed of $18 \mathrm{~km} \mathrm{~h}^{-1}$, each latitude bin was traversed in $\sim 6 \mathrm{~h}$, implying that the binned detection limits of these compounds were $\sim 4,2$, and $2 \mu$ moles $\mathrm{m}^{-2} \mathrm{~d}^{-1}$. By this definition, $\sim 90 \%$ of the latitudinally averaged methanol flux exceeded the detection limit. For acetone, this percentage was $\sim 80 \%$ for the Northern Hemisphere and only $\sim 10 \%$ for the Southern. Only $\sim 30 \%$ of the EC acetaldehyde flux exceeded the detection limit for the entire transect.

Estimated following Blomquist et al. (2010) with the empirical constant $a$ set to 1 , hourly flux uncertainty was 30$40 \%$ for methanol and 60-140\% for acetone in the Northern Hemisphere, and even greater for acetaldehyde. We estimate the contribution to total flux uncertainty from instrumental noise to be about 40,60 , and $80 \%$ for methanol, acetone, and acetaldehyde during the period from 31 October to 1 November. Between 3 November and 16 November, the dwell time at $m / z 33$ was doubled to $200 \mathrm{~ms}$ to compensate for the lower atmospheric methanol concentration (and natural variance) in the South Atlantic, which lowered the detection limit by $\sim 40 \%$ for this compound. Among the three OVOCs, improving sensitivity and reducing instrumental noise would have the greatest benefit for the detection of acetaldehyde flux.

\section{Appendix D: Motion-sensitivity in EC fluxes}

Methanol flux demonstrated a motion-sensitivity in large swell. In Fig. A1, the averaged variance spectra of methanol and acetone over $\sim 10 \mathrm{~h}$ on 13 November are shown, when wind speeds were about $16 \mathrm{~m} \mathrm{~s}^{-1}$ and the vertical platform variance over $2 \mathrm{~m}^{2} \mathrm{~s}^{-2}$. An unexpected peak can be seen in the raw methanol spectrum between 0.1 and $0.2 \mathrm{~Hz}$ (the frequency of ship's motion), which manifest as positive/negative peaks in the corresponding methanol: $w$ cospectrum. This artifact was not observed in the raw acetone spectrum. Further analysis yielded spurious correlations between the atmospheric methanol concentration and vertical ship acceleration as well as displacement.

The correlation between methanol concentration and acceleration was a motion-induced artifact with the PTR-MS. In heavy seas the source water vapor flow, nominally steady, fluctuated by up to $\sim 0.5 \mathrm{sccm}$ around the set value of $9.0 \mathrm{sccm}$, leading to sinusoidal variations in the $\mathrm{O}_{2}^{+}$signal. This motion-sensitivity propagated to $m / z 33$ in the form of ${ }^{16} \mathrm{O}^{17} \mathrm{O}^{+}$, increasing the apparent variability of the methanol signal. In contrast, acetone concentration and ship's motion did not significantly correlate. The correlation of methanol concentration with platform displacement may be due to vertical heaving of the ship across a concentration gradient. From similarity theory, Yang et al. (2013b) estimated an average vertical gradient of $0.002 \mathrm{ppb} \mathrm{m}^{-1}$ for methanol within the surface layer of the atmosphere. In heavy seas, the bow of the ship may heave with a $10 \mathrm{~m}$ amplitude and thus induce an apparent variation of $0.02 \mathrm{ppb}$, which would represent $\sim 14 \%$ of the observed $\sigma$ at a dwell time of $200 \mathrm{~ms}$. Blomquist et al. (2010) showed a worst-case error of $18 \%$ in the measured air-sea flux in an analysis of dimethylsulfide due to this motion gradient effect. Acetone concentration did not correlate with platform displacement during this period, likely because the saturation of acetone was $\sim 100 \%$ (i.e. no vertical concentration gradient).

To address these artifacts, we decorrelate the atmospheric methanol concentration with the ship's vertical acceleration and displacement. This effectively removed the artificial peaks in the variance and covariance spectra between $0.1-0.2 \mathrm{~Hz}$ while preserving the signal at other frequencies. The corrected methanol:w cospectrum is reasonably fitted by the theoretical Kaimal spectrum. The decorrelation reduced the magnitude of the methanol flux by $2.5 \mu$ moles $\mathrm{m}^{-2} \mathrm{~d}^{-1}$ $(24 \%)$ on average for the entire AMT-22 cruise. In heavy seas (vertical platform variance $>2 \mathrm{~m}^{2} \mathrm{~s}^{-2}$ ), the reduction in flux 
was up to $10 \mu$ moles $\mathrm{m}^{-2} \mathrm{~d}^{-1}$. We apply an analogous decorrelation to $T_{\mathrm{a}}$ from the sonic anemometer, which is also subject to the vertical gradient effect but should be insensitive to the ship's acceleration. Decorrelation reduces the magnitude of the sensible heat flux by only a few percent in heavy seas, confirming that most of the motion-related artifact in methanol flux was related to the PTR-MS.

\section{Appendix E: Funnel-induced artifacts in acetaldehyde and acetone flux}

Contamination from the plastic funnel, if uncorrelated with the vertical wind velocity, in theory should not affect the EC flux. However, artifacts are apparent in the acetaldehyde and acetone cospectra at frequencies over $\sim 0.1 \mathrm{~Hz}$ in the Northern Hemisphere (e.g. Fig. 3). Contamination from the funnel may have varied with the airflow through the inlet as well as the resultant temperature fluctuation. In the tropical North Atlantic and under strong sunlight, we observed greater emissions from the funnel when the ship was stationary than when the ship was underway, presumably due to changes in the relative wind speeds (and so cooling rates). Decorrelation of acetone and acetaldehyde concentrations with ship's motion proved ineffective at removing these artifacts, forcing us to discard fluxes when the cospectra were severely distorted in the Northern Hemisphere (e.g. 24-28 October for acetone).

\section{Appendix F: Potential contribution to OVOC fluxes due to density fluctuations}

Temperature and pressure in the reaction chamber are controlled by the PTR-MS, while the long inlet tubing likely dampens most of the water vapor flux. Thus a "Webb" correction (Webb et al., 1980) should not be necessary. Nevertheless, it is instructive to examine the magnitude of the potential contribution from density fluctuations to EC flux. From in situ meteorological and surface ocean data, the COARE model predicts a mean vertical wind velocity $(\bar{w})$ of $-1.0 \times 10^{-4}$ to $3.9 \times 10^{-4} \mathrm{~m} \mathrm{~s}^{-1}$ (mean of $0.9 \times 10^{-4} \mathrm{~m} \mathrm{~s}^{-1}$ ) for the entire cruise. Multiplying by $\bar{w}$ the atmospheric methanol concentration leads to a mean (maximum) apparent flux of $0.13(0.57) \mu$ moles $\mathrm{m}^{-2} \mathrm{~d}^{-1}$, which is $\sim 2$ orders of magnitude lower than the observed flux. For acetaldehyde and acetone, because of their lower atmospheric concentrations the "Webb" terms are even smaller. 
Acknowledgements. This work is supported by the United States National Science Foundation (grant no. OISE-1064405) and the PML Kingsland Fellowship. The AMT cruise is supported by the UK Natural Environment Research Council National Capability funding to Plymouth Marine Laboratory and the National Oceanography Centre, Southampton. This is a contribution to the international SOLAS and IMBER projects and represents contribution number 245 of the AMT program. The first author would like to thank P. Mason, A. Staff, and S. Howell for instrumentation support, J. Stephens and F. Hopkins for equipment set up, G. Tilstone for CDOM/primary production data, T. Bell, and J. Dixon for scientific input, and finally B. Huebert and C. Fairall for continued guidance.

Edited by: D. Woolf

\section{References}

Bariteau, L., Helmig, D., Fairall, C. W., Hare, J. E., Hueber, J., and Lang, E. K.: Determination of oceanic ozone deposition by shipborne eddy covariance flux measurements, Atmos. Meas. Tech., 3, 441-455, doi:10.5194/amt-3-441-2010, 2010.

Beale, R., Dixon, J., Liss, P., and Nightingale, P.: Quantification of oxygenated volatile organic compounds in seawater by membrane inlet-proton transfer reaction/mass spectrometry, Anal. Chim. Acta 706, 128-134, 2011.

Beale, R., Dixon, J., Arnold, S., Liss, P., and Nightingale, P.: Methanol, acetaldehyde and acetone in the surface waters of the Atlantic Ocean, J. Geophys. Res., 118, 1-14, doi:10.1002/jgrc.20322, 2013.

Bell, R. P., Rand, M. H., and Wynne-Jones, K. M. A.: Kinetics of the hydration of acetaldehyde, Trans. Faraday Soc., 52, 1093-1102, 1956.

Bell, R. P. and Avans, P. G.: Kinetics of the dehydration of methylene glycol in aqueous solution. Proc. R. Sot. London, Ser. A, 291, 297-321, 1966.

Bell, T. G., Poulton, A. J., and Malin, G.: Strong linkages between dimethylsulphoniopropionate (DMSP) and phytoplankton community physiology in a large subtropical and tropical Atlantic Ocean data set, Global Biogeochem. Cy., 24, GB3009, doi:10.1029/2009GB003617, 2010.

Benkelberg, H. J., Hamm, S., and Warneck, P.: Henry's low coefficients for aqueous solutions of acetone, acetaldehyde and acetonitrile, equilibrium constants for the addition-compounds of acetone and acetaldehyde with bisulfite, J. Atmos. Chem. 20, 1734, 1995.

Blomquist, B., Fairall, C. W., Huebert, B. J., Kieber, D., and Westby, G.: DMS sea-air transfer velocity: Direct measurements by eddy covariance and parameterization based on the NOAA/COARE gas transfer model, Geophys. Res. Lett., 33, L07601, doi:10.1029/2006GL025735, 2006.

Blomquist, B. W., Huebert, B. J., Fairall, C. W., and Faloona, I. C.: Determining the sea-air flux of dimethylsulfide by eddy correlation using mass spectrometry, Atmos. Meas. Tech., 3, 1-20, doi:10.5194/amt-3-1-2010, 2010.

Carpenter, L. J., Archer, S. D., and Beale, R.: Ocean-atmosphere trace gas exchange, Chem. Soc. Rev., 41, 6473-6506, 2012.

Carpenter, L. J., Lewis, A. C., Hopkins, J. R., Read, K. A., Longley, I. D., and Gallagher, M. W.: Uptake of methanol to the North
Atlantic Ocean surface, Global Biogeochem. Cy., 18, GB4027, doi:10.1029/2004GB002294, 2004.

Dachs, J., Calleja, M. L., Duarte, C. M., del Vento, S., Turpin, B., Polidori, A., Herndl, G. J., and Agust, S.: High atmosphereocean exchange of organic carbon in the NE subtropical Atlantic, Geophys. Res. Lett., 32, L21807, doi:10.1029/2005GL023799, 2005.

Dixon, J. L, Beale, R., and Nightingale, P. D.: Production of methanol, acetaldehyde, and acetone in the Atlantic Ocean, Geophys. Res. Lett., 40, 1-6, doi: 10.1002/grl.50922, 2013.

Duce, R. A., Liss, P. S., Merrill, J. T., Atlas, E. L., Buat-Menard, P., Hicks, B. B., Miller, J. M., Prospero, J. M., Arimoto, R., Church, T. M., Ellis, W., Galloway, J. N., Hansen, L., Jickells, T. D., Knap, A. H., Reinhardt, K. H., Schneider, B., Soudine, A., Tokos, J. J., Tsunogai, S., Wollast, R., and Zhou, M.: The Atmospheric Input of Trace Species to the World Ocean, Global Biogeochem. Cy., 5, 193-259, 1991.

Edson, J., Hinton, A., Prada, K., Hare, J., and Fairall, C.: Direct covariance flux estimates from mobile platforms at sea, J. Atmos. Ocean. Technol., 15, 547-562, 1998.

Fairall, C. W., Bradley, E. F., Rogers, D. P., Edson, J. B., and Young, G. S.: Bulk parameterization of air-sea fluxes for Tropical OceanGlobal Atmosphere Coupled-Ocean Atmosphere Response Experiment, J. Geophys. Res., 101, 3747-3764, 1996.

Fairall, C. W., Yang, M., Bariteau, L., Edson, J. B., Helmig, D., McGillis, W., Pezoa, S., Hare, J. E., Huebert, B., and Blomquist, B.: Implementation of the Coupled Ocean-Atmosphere Response Experiment flux algorithm with $\mathrm{CO}_{2}$, dimethyl sulfide, and $\mathrm{O}_{3}, \mathrm{~J}$. Geophys. Res., 116, C00F09, doi:10.1029/2010JC006884, 2011.

Fischer, E. V., Jacob, D. J., Millet, D. B., Yantosca, R. M., and Mao, J.: The role of the ocean in the global atmospheric budget of acetone, Geophys. Res. Lett., 39, L01807, doi:10.1029/2011GL050086, 2012.

Guenther, A., Geron, C., Pierce, T., Lamb, B., Harley, P., and Fall, R.: Natural emissions of non-methane volatile organic compounds; carbon monoxide, and oxides of nitrogen from North America, Atmos. Environ., 34, 2205-2230, 2000.

Heald, C. L., Goldstein, A. H., Allan, J. D., Aiken, A. C., Apel, E., Atlas, E. L., Baker, A. K., Bates, T. S., Beyersdorf, A. J., Blake, D. R., Campos, T., Coe, H., Crounse, J. D., DeCarlo, P. F., de Gouw, J. A., Dunlea, E. J., Flocke, F. M., Fried, A., Goldan, P., Griffin, R. J., Herndon, S. C., Holloway, J. S., Holzinger, R., Jimenez, J. L., Junkermann, W., Kuster, W. C., Lewis, A. C., Meinardi, S., Millet, D. B., Onasch, T., Polidori, A., Quinn, P. K., Riemer, D. D., Roberts, J. M., Salcedo, D., Sive, B., Swanson, A. L., Talbot, R., Warneke, C., Weber, R. J., Weibring, P., Wennberg, P. O., Worsnop, D. R., Wittig, A. E., Zhang, R., Zheng, J., and Zheng, W.: Total observed organic carbon (TOOC) in the atmosphere: a synthesis of North American observations, Atmos. Chem. Phys., 8, 2007-2025, doi:10.5194/acp-8-20072008, 2008.

Heikes, B. G., Chang, W. N., Pilson, M. E. Q., Swift, E., Singh, H. B., Guenther, A., Jacob, D. J., Field, B. D., Fall, R., Riemer, D., and Brand, L.: Atmospheric methanol budget and ocean implication, Global Biogeochem. Cy., 16, 1133, doi:10.1029/2002GB001895, 2002.

Hicks, B, Wesely, M, Lindberg, S, Bromberg, S. Proceedings of the NAPAP Workshop on Dry Deposition, Harpers Ferry, W. Va., 25-27, p. 77, 1986. 
Hoover, T. E. and Berkshire, D. C.: Effects of hydration on carbon dioxide exchange across an air-water interface. J. Geophys. Res., 74, 456-464, 1969.

Jacob, D. J., Field, B. D., Jin, E. M., Bey, I., Li, Q., Logan, J. A., Yantosca, R. M., and Singh H. B., Atmospheric budget of acetone, J. Geophys. Res., 107, 4100, doi:10.1029/2001JD000694, 2002.

Jacob, D. J., Field, B. D., Li, Q. B., Blake, D. R., de Gouw, J., Warneke, C., Hansel, A., Wisthaler, A., Singh, H. B., and Guenther, A.: Global budget of methanol: Constraints from atmospheric observations, J. Geophys. Res., 110, D08303, doi:10.1029/2004JD005172, 2005.

Johnson, M.: A numerical scheme to calculate temperature and salinity dependent air-water transfer velocities for any gas. Ocean Sci. 6, 913-932, doi:10.5194/os-6-913-2010, 2010.

Jardine, K., Harley, P., Karl, T., Guenther, A., Lerdau, M., and Mak, J. E.: Plant physiological and environmental controls over the exchange of acetaldehyde between forest canopies and the atmosphere, Biogeosciences, 5, 1559-1572, doi:10.5194/bg-5-15592008, 2008.

Kaimal, J., Wyngaard, J., Izumi, Y., and Coté, O.: Spectral characteristics of surface layer turbulence, Q. J. Roy. Meteorol. Soc., 98, 563-589, doi:10.1002/qj.49709841707, 1972.

Kameyama, S., Tanimoto, H., Inomata, S., Tsunogai, U., Ooki, A., Takeda, S, Obata, H., Tsuda, A., and Uematsu, M.: Highresolution measurement of multiple volatile organic compounds dissolved in seawater using equilibrator inlet-proton transfer reaction-mass spectrometry (EI-PTR-MS). Mar. Chem., 122, 59-73, 2010.

Karl, T., Guenther, A., Lindinger, C., Jordan, A., Fall, R., and Lindinger, W.: Eddy covariance measurements of oxygenated volatile organic compound fluxes from crop harvesting using a redesigned proton-transfer-reaction mass spectrometer, J. Geophys. Res., 106, 24157-24167, doi:10.1029/2000JD000112, 2001.

Karl, T., Potosnak, M., Guenther, A., Clark, D., Walker, J., Herrick, J. D., and Geron, C.: Exchange processes of volatile organic compounds above a tropical rain forest: Implications for modeling tropospheric chemistry above dense vegetation, J. Geophys. Res., 109, D18306, doi:10.1029/2004JD004738, 2004.

Kieber, R. J., Zhou, X., and Mopper, K.: Formation of carbonyl compounds from UV-induced photodegradation of humic substances in natural waters: Fate of riverine carbon in the sea. Limnol. Oceanogr., 35: 1503-1515, 1990.

Kurz, J. L. and Coburn, J. I.: The hydration of acetaldehyde. II. Transition-state characterization, J. Am. Chem. Soc., 89, 35243528, 1967.

Lerot, C., Stavrakou, T., De Smedt, I., Mueller, J.-F., and Van Roozendael, M.: Glyoxal vertical columns from GOME-2 backscattered light measurements and comparisons with a global model, Atmos. Chem. Phys., 10, 12059-12072, doi:10.5194/acp10-12059-2010, 2010

Lewis, A. C., Hopkins, J. R., Carpenter, L. J., Stanton, J., Read, K. A., and Pilling, M. J.: Sources and sinks of acetone, methanol, and acetaldehyde in North Atlantic marine air, Atmos. Chem. Phys., 5, 1963-1974, doi:10.5194/acp-5-1963-2005, 2005.

Lindinger, W., Hansel A., and Jordan, A.: On-line monitoring of volatile organic compounds at pptv levels by means of Proton-
Transfer-Reaction Mass Spectrometry (PTR-MS). Medical applications, food control and environmental research, Int. J. Mass Spectrom. Ion Proc., 173, 191-241, 1998.

Liss, P. S. and Slater, P. G.: Flux of gases across the air-sea interface, Nature, 247, 181-184, doi:10.1038/247181a0, 1974.

Marandino, C. A., De Bruyn, W. J., Miller, S. D., Prather, M. J., and Saltzman, E. S.: Oceanic uptake and the global atmospheric acetone budget, Geophys. Res. Lett., 32, L15806, doi:10.1029/2005GL023285, 2005.

Millet, D. B., Jacob, D. J., Turquety, S., Hudman, R. C., Wu, S., Fried, A., Walega, J., Heikes, B. G., Blake, D. R., Singh, H. B., Anderson, B. E., and Clarke, A. D.: Formaldehyde distribution over North America: Implications for satellite retrievals of formaldehyde columns and isoprene emission, J. Geophys. Res., 111, D24S02, doi:10.1029/2005JD006853, 2006.

Millet, D. B., Jacob, D. J., Custer, T. G., de Gouw, J. A., Goldstein, A. H., Karl, T., Singh, H. B., Sive, B. C., Talbot, R. W., Warneke, C., and Williams, J.: New constraints on terrestrial and oceanic sources of atmospheric methanol, Atmos. Chem. Phys., 8, 6887-6905, doi:10.5194/acp-8-6887-2008, 2008.

Mopper, K. and Kieber, D. J.: Distribution and biological turnover of dissolved organic compounds in the water column of the Black Sea, Deep-Sea Res., 38, 1021-1047, 1991.

Read K., Carpenter, L., Arnold, S., Beale, R., Nightingale, P., Hopkins, J., Lewis, A., Lee. J, Mendes, L., and Pickering S.: Multiannual Observations of Acetone, Methanol, and Acetaldehyde in Remote Tropical Atlantic Air: Implications for Atmospheric OVOC Budgets and Oxidative Capacity, Environ. Sci. Technol., 46, 11028-11039, 2012.

Sander, R.: Compilation of Henry's Law constants for inorganic and organic species of potential importance in environmental chemistry (Version 3), http://www.henrys-law.org (last access: 19 March 2014), 1999.

Schecker, H. and Schultz, G.: Untersuchungen zur Hydrationskinetik von Formaldehyd in waessriger Loesung, Z. Phys. Chem., Neue Folge, 65, 221-224, 1969.

Singh, H., Chen, Y., Tabazadeh, A., Fukui, Y., Bey, I., Yantosca, R., Jacob, D., Arnold, F., Wohlfrom, K., Atlas, E., Flocke, F., Blake, D., Blake, N., Heikes, B., Snow, J., Talbot, R., Gregory, G., Sachse, G., Vay, S., and Kondo, Y.: Distribution and fate of selected oxygenated organic species in the troposphere and lower stratosphere over the Atlantic, J. Geophys. Res., 105, 3795-3805, 2000.

Singh, H. B., Salas, L. J., Chatfield, R. B., Czech, E., Fried, A., Walega, J., Evans, M. J., Field, B. D., Jacob, D. J., Blake, D., Heikes, B., Talbot, R., Sachse, G., Crawford, J. H., Avery, M. A., Sandholm, S., and Fuelberg, H.: Analysis of the atmospheric distribution, sources, and sinks of oxygenated volatile organic chemicals based on measurements over the Pacific during TRACE-P, J. Geophys. Res., 109, D15S07, doi:10.1029/2003JD003883, 2004.

Singh, H. B., Tabazadeh, A., Evans, M. J., Field, B. D., Jacob, D. J., Sachse, G., Crawford, J. H., Shetter, R., and Brune, W. H.: Oxygenated volatile organic chemicals in the oceans: Inferences and implications based on atmospheric observations and air-sea exchange models, Geophys. Res. Lett., 30, 1862, doi:10.1029/2003GL017933, 2003.

Sinreich, R., Coburn, S., Dix, B., and Volkamer, R.: Ship-based detection of glyoxal over the remote tropical Pacific Ocean, 
Atmos. Chem. Phys., 10, 11359-11371, doi:10.5194/acp-1011359-2010, 2010.

Snider, J. and Dawson, G.: Tropospheric light alcohols, carbonyls, and acetonitrile: Concentrations in the southwestern United States and Henry's law data, J. Geophys. Res. 90, 3797-3805, 1985.

Spirig, C., Neftel, A., Ammann, C., Dommen, J., Grabmer, W., Thielmann, A., Schaub, A., Beauchamp, J., Wisthaler, A., and Hansel, A.: Eddy covariance flux measurements of biogenic VOCs during ECHO 2003 using proton transfer reaction mass spectrometry, Atmos. Chem. Phys., 5, 465-481, doi:10.5194/acp-5-465-2005, 2005.

Stavrakou, T., Mueller, J.-F., De Smedt, I., Van Roozendael, M., Kanakidou, M., Vrekoussis, M., Wittrock, F., Richter, A., and Burrows, J. P.: The continental source of glyoxal es- timated by the synergistic use of spaceborne measurements and inverse modelling, Atmos. Chem. Phys., 9, 8431-8446, doi:10.5194/acp9-8431-2009, 2009.

Taddei, S., Toscano, P., Gioli, B., Matese, A., Miglietta, F., Vaccari, F. P., Zaldei, A., Custer, T., and Williams, J.: Carbon dioxide and acetone air-sea fluxes over the Southern Atlantic, Environ. Sci. Technol., 43, 5218-5222, 2009.

Tanimoto, H., Kameyama, S., Iwata, T., Inomata, S., and Omori, Y.: Measurement of air-sea exchange of dimethyl sulfide and acetone by PTR-MS coupled with gradient flux technique, Environ. Sci. Technol., 48, 526-533, doi:10.1021/es4032562, 2014.

Webb, E. D., Pearman, G. I., and Leuning, R.: Correction of flux measurements for density due to heat and water vapor transport, Q. J. Roy. Meteor. Soc., 106, 85-100, doi:10.1002/qj.49710644707, 1980.

Williams, J., Holzinger, R., Gros, V., Xu, X., Atlas, E., and Wallace, D. W. R.: Measurements of organic species in air and seawater from the tropical Atlantic, Geophys. Res. Lett., 31, L23S06, doi:10.1029/2004GL020012, 2004.
Woolf, D. K.: Bubbles and their role in gas exchange, in The Sea Surface and Global Change, edited by: Duce, R. and Liss, P., Cambridge Univ. Press, New York, 173-205, doi:10.1017/CBO9780511525025.007, 1997.

Wróblewski, T., Ziemczonek, L. Alhasan, A. M., and Karwasz, G. P.: Ab initio and density functional theory calculations of proton affinities for volatile organic compounds, Eur. Phys. J. Spec. Top., 144, 191-195, doi:10.1140/epjst/e2007-00126-7, 2007.

Yang, M., Beale, R., Smyth, T., and Blomquist, B.: Measurements of OVOC fluxes by eddy covariance using a proton-transferreaction mass spectrometer - method development at a coastal site, Atmos. Chem. Phys., 13, 6165-6184, doi:10.5194/acp-136165-2013, 2013a.

Yang, M., Nightingale, P., Beale, R., Liss, P., Blomquist, B., and Fairall, C.: Atmospheric deposition of methanol over the Atlantic Ocean, P. Natl. Acad. Sci., doi:10.1073/pnas.1317840110, 110, 20034-20039, 2013b.

Zhao, J. and Zhang, R. Y.: Proton transfer reaction rate constants between hydronium ion $\left(\mathrm{H}_{3} \mathrm{O}(+)\right)$ and volatile organic compounds, Atmos. Environ., 38, 2177-2185, 2004.

Zhou, X. and Mopper, K.: Apparent partition coefficients of 15 carbonyl compounds between air and seawater and between air and freshwater; implications for air-sea exchange, Environ. Sci. Technol., 24, 1864-1869, 1990.

Zhou, X. and Mopper, K.: Photochemical production of lowmolecular-weight carbonyl compounds in seawater and surface microlayer and their air-sea exchange, Mar. Chem., 56, 201-213, 1997. 